\title{
有机合成在创新药物研发中的应用与进展
}

\author{
张 雯* 聂 炎张英俊 \\ (广东东阳光集团药业研究院 东莞 523871)
}

\begin{abstract}
摘要 论述了现代有机合成化学在一些创新药物尤其是 “重磅炸弹” 新药，如索非布韦(Sofosbuvir)、利伐沙班 (Rivaroxaban)、恩杂鲁胺(Enzalutamide)、卡格列净(Canagliflozin)和托法替尼(Tofacitinib), 研发中的应用和进展, 突出 显示了催化过程、闭环复分解反应、钯催化的交叉偶联、绿色化学和叠缩工艺等合成方法. 通过数十个新分子实体药 物发明历程的回顾, 诠释了现代有机合成在新药开发中的重要作用.
\end{abstract}

关键词 药物; 药物合成; 有机合成; 合成艺术

\section{Application and Progress of Organic Synthesis in the Discovery of Innovative Drugs}

\author{
Zhang, $\mathrm{Ji}^{*} \quad$ Nie, Biao Zhang, Yingjun \\ (HEC Pharm Group, HEC R\&D Center, Dongguan 523871)
}

\begin{abstract}
This article reviews the application and progress of modern synthetic methods to deliver several innovative drugs, especially the blockbusters, such as sofosbuvir, rivaroxaban, enzalutamide, canagliflozin and tofacitinib. Some of the modern synthetic methods, for example catalytic processes, application of ring-closing metathesis, palladium catalyzed cross-coupling, green chemistry and telescoping of processes, are highlighted. The exciting journey from discovering these new molecular entities, especially those which are first-in-class with the synthesis of a dozen of approved drugs, is described as case studies to fully illustrate the important role of modern organic synthesis for successful drug discovery and development.

Keywords drugs; drug synthesis; organic synthesis; art in drug synthesis
\end{abstract}

从胜利的三重唱(A Triumphant Trio)到欢庆的四重 奏(The Quartet of Celebration)-一中国科学院上海有机 化学研究所走出的四位化学家和四个创新药物：普纳替
尼 (Ponatinib), Ganetespib, TH-302 和 威 罗 菲 尼 (Vemurafenib).<smiles>Cc1ccc(C(=O)Nc2ccc(CN3CCN(C)CC3)c(C(F)(F)F)c2)cc1C#Cc1cnc2cccnn12</smiles><smiles>CC(C)c1cccc(-c2nn(-c3ccccc3)c(=O)n2-c2ccccc2)c1</smiles><smiles>Cn1c(COP(=O)(NCBr)NCBr)cnc1[N+](=O)[O-]</smiles>

TH-302 (3)<smiles>CCCS(=O)(=O)Nc1ccc(F)c(C(=O)c2c[nH]c3ncc(-c4ccc(Cl)cc4)cc23)c1F</smiles>

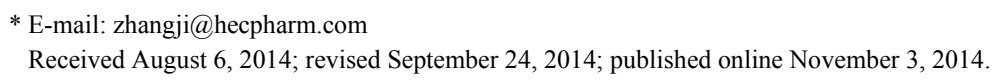

Project supported by the Guangdong Innovative and Entrepreneurial Research Team Program (No. 201301Y0105381261).

广东省引进创新创业团队计划(No. 201301Y0105381261)资助项目. 
2013 年 10 月 14 日美国化学会出版的化学与工程新 闻(Chem. \& Eng. New) 以图文并茂的形式, 用胜利的三 重唱(A Triumphant Trio)为标题, 介绍了 1989 年就读于 中国科学院上海有机化学研究所(SIOC)的三位化学家 在美国生物制药业进行创新药物研发并取得突破性成 果的感人故事 ${ }^{[1 a]}$. 故事的三位主角分别是三个临床创新 药物的发明家. 他们是上市癌症新药 Ponatinib 的发明 者之一, Ariad 制药的黄卫生 ${ }^{[1 b]}$; 临床癌症新药 Ganetesib 的发明者之一, 麻塞诸塞州 Synta 制药的英伟

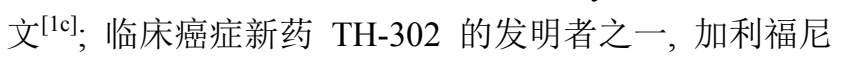
亚州 Threshold 制药的段建新 ${ }^{[\mathrm{d}]}$.

黄卫生发明的新药普纳替尼(Ponatinib) ${ }^{[2]}$, 作为一 种治疗慢性粒细胞白血病(CML)的创新药物, 仅经过临 床 II 期就获美国食品与药品监督管理局(FDA)快速批准 (2012 年 12 月 14 日). 2013 年的年销售额达到四千五百 万美元. 但由于该药对一些服药患者会造成严重血栓的 副作用, FDA 于 2013 年 10 月 20 日要求普纳替尼从市场 下架. 经过临床风险收益评估后, FDA 于 2013 年的 12 月 20 日再次允许该药上市, 但是要求说明书加上警示 标签. 这从一个侧面反映出创新药物在带来巨额利润的 同时, 也面临着潜在的安全风险.

普纳替尼的合成方法如 Scheme 1 所示, 它是将含 氮芳香杂环和芳香环经过 $\mathrm{C} \equiv \mathrm{C}$ 连接起来的多靶点 (Pan-BCR-ABL) 的小分子激酶抑制剂. 在药物研发和生 产过程中, 两次活用并巧用钯催化的 Sonogashira 偶联 反应, 活泼中间体不加分离, 采纳叠缩工艺 ${ }^{[3]}$, 高产率 地制备关键中间体 7, 不失为创新和绿色化学在药物合 成方面的具体实践 ${ }^{[4]}$. 在药物分子中将含氮杂芳环和芳 环用 $\mathrm{C} \equiv \mathrm{C}$ 连接起来的新药是极为罕见的(含有端位炔 的药物有 Erlotinib; 用 $\mathrm{C} \equiv \mathrm{C}$ 在分子内连的药物有 Efavirenz). $\mathrm{C} \equiv \mathrm{C}$ 和芳杂环在分子内连接, 人体体液偏 酸性的条件下它应该是良好的 Michael 受体, 这是否是 造成血栓或基因毒性副作用的原因, 仍有待进一步的研 究验证.

2011 年获 FDA 批准的另一个皮肤癌用药威罗菲尼 (Vemurafenib)的发明者之一也是中国科学院上海有机 化学研究所毕业的张家仲. 他参与发明的威罗菲尼 (Vemurafenib) 是 B-raf 激酶抑制剂, 是首个黑素瘤个性 化靶向药物 ${ }^{[5]}$, 也是近 30 年来黑素瘤治疗取得的重大突 破!

归总起来, 来自 SIOC 毕业的新药发明者应该是四 位化学家, 组成欢庆的四重奏(The Quartet of Celebration).

中国近 30 年化学学科的进步, 尤其是有机化学的 飞跃发展是有目共睹的 ${ }^{[1 \mathrm{a}, 1 \mathrm{f}]}$. 在许多跨国药企, 留下了

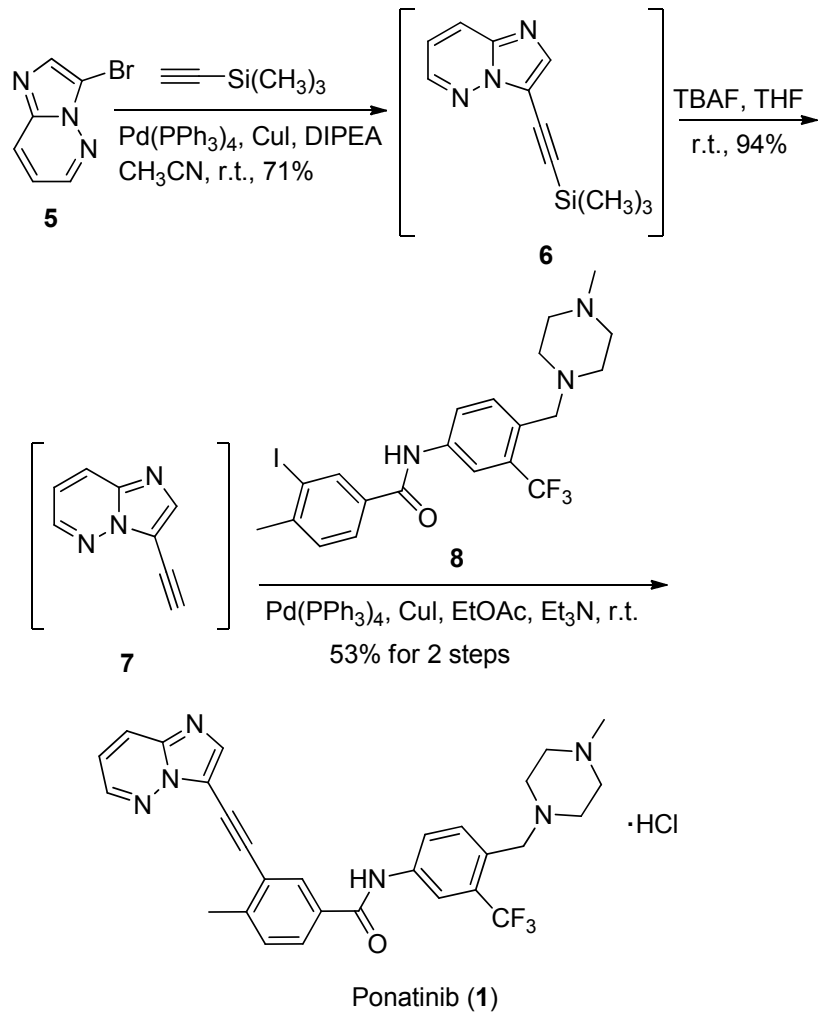

图式 1 普纳替尼的合成

Scheme 1 Synthesis of ponatinib

中国培养的、又接受现代西方教育的优秀华人化学工作 者勤劳的身影, 一个个创新药物的诞生, 彰显着他们的 聪明和才智. 与此同时, 国家新药创制重大专项的实施, 极大推进了中国自主专利新药的研制进程. 国内新药研 发水平正在不断提高, 据统计, 2003 年发表在 $J . M e d$. Chem. 杂志上来自中国本土的研究论文仅为 3\%, 而 2012 年这一比例已经上升到 $8 \%^{[1] a]}$, 这对立志从事有机化学和 药物化学的年轻人来说是一种巨大的激励和鞕策!

\section{1 老药尼鲁米特 (Nilutamide)、比卡鲁胺 (Bicalutamide)和 RU59063 的改造和推陈出 新: 前列腺癌新药恩杂鲁胺(Enzalutamide)的 出现}

诺贝尔奖得主 James Black 曾经说过: 研究新药最 好的方式是从老药入手! 这也说明为什么当一个创新 药物出现后, 蜂拥而来的是对其结构的进一步改造和修 饰, 造就了许多所谓模仿 (me-too) 新药. 对药物化学家 来说, 有良好的合成方式和手段, 辅之有必备的药学背 景知识, 往往能创造出更好 (me-better), 甚至最好 (me-best)的重磅新药.

2012 年 FDA 批准恩杂鲁胺(Enzalutamide, 11)治疗 晚期(转移)前列腺癌. 这是过去 3 年来上市的第四个转 
移性前列腺癌药物, 被视为目前最好的前列腺癌药物. 恩杂鲁胺是一种雄激素受体抑制剂, 抑制雄激素受体核 转位及与 DNA 的相互作用 ${ }^{[7]}$.

Nilutamide (9), 1978
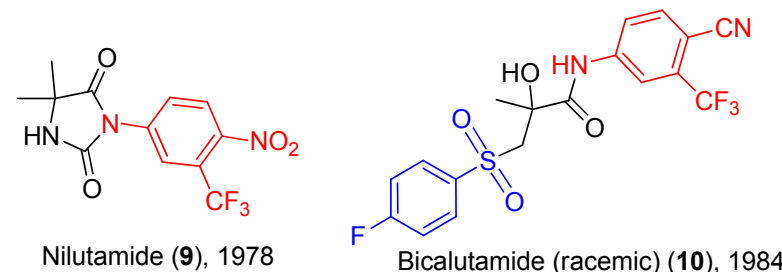

Bicalutamide (racemic) (10), 1984<smiles>CNC(=O)c1ccc(N2C(=S)N(c3ccc(C#N)c(F)c3)C(=O)C2(C)C)cc1F</smiles>

尼鲁米特(Nilutamide, 9) 是最早的前列腺癌用药, 含硝基的三氟甲基苯亚酰胺芳香环是药效基团. 后来改 进的前列腺癌用药是外消旋的比卡鲁胺(Bicalutamide, 10), 其结构特点是将硝基改换为腈基, 并引入含氟苯 的砜类直链. 最近获批的恩杂鲁胺从化学结构来看, 它 综合了两个老药结构特点, 成为了新型的前列腺癌药 物. 由此不难看出, 结构改造是合成的技巧和艺术的体 现. 同时这是一个含有三氟甲基芳香胺药效基的小分子 药物, 含氟新药的研究是当前创新药物研究的一个热点 和重点 ${ }^{[6]}$.

恩杂鲁胺也是源于对雄激素受体有高度亲和力的 先导化合物 RU59063 (12) ${ }^{[8]}$, 经过系统修饰和改造而成. 加利福尼亚大学洛杉矶分校(UCLA)化学系的 Jung 教授 和美国斯隆-凯特琳癌症中心(Sloan Kettering Cancer Center)的肿瘤病理学家 Sawyers 教授围绕乙内酰硫嫝母 核植入有效的药效团, 通过对通式化合物 $13 \sim 22$ 构效 关系的认真研究和分析, 终于找到理想的药物分子 ${ }^{[9]}$.<smiles>CC1(C)C(=O)N(c2ccc(C#N)c(C(F)(F)F)c2)C(=S)N1CCCCO</smiles>

RU 59063 (12)

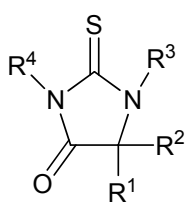

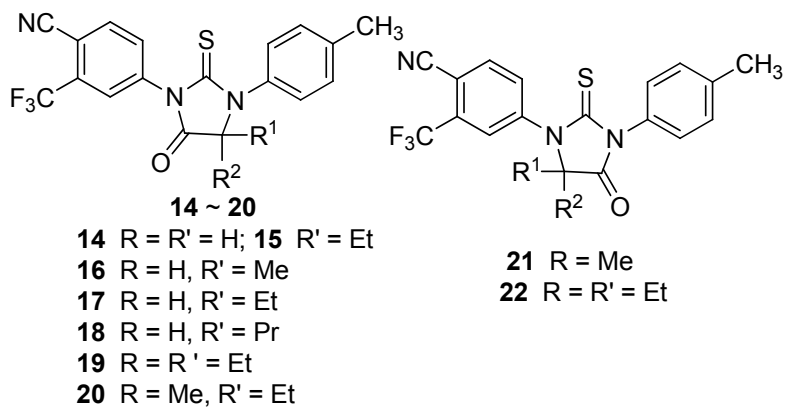

从专利公布的合成工艺(Scheme 2$)^{[10]}$ 来看，恩杂鲁 胺合成方法简单实用. 其关键反应是采用铜(I)盐催化的 Ullmann 胺化反应，亮点之一是充分考虑到了氟代甲酰 胺基溴苯 25 的反应活性，采用了未经保护的、水溶性极 佳的 2-甲基-2-氨基丙酸为氨化试剂(同时也免除了不必 要的羧基保护和去保护)、用 2-乙酰基环己酮为催化剂 配体, 在碱性条件和偶极溶剂 $\left(\mathrm{K}_{2} \mathrm{CO}_{3}, \mathrm{DMF} / \mathrm{H}_{2} \mathrm{O}\right)$ 的存 在下，非常有效(两步 $90 \%$ 的收率)地制备了游离的取代 氨基酸 26, 并在相同的反应媒介下，高产率(95\%)地制 备了氨基酸甲酯 27.
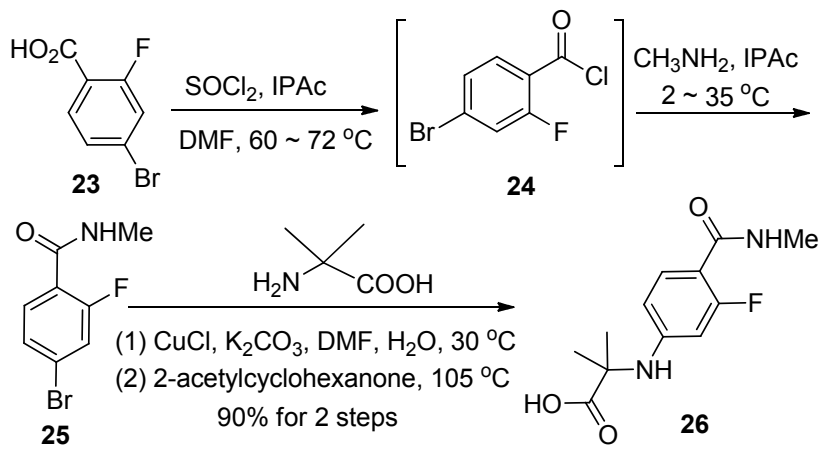<smiles>CNC(=O)c1ccc(NC(C)(C)C(=O)OC)cc1F</smiles><smiles>CS(=O)(=O)Nc1ccc(N)c(C(F)(F)F)c1</smiles>

IPAc, $84^{\circ} \mathrm{C}$ $78 \%$

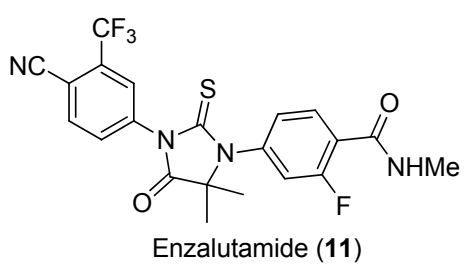

图式 2 恩杂鲁胺的合成

Scheme 2 Synthesis of enzalutamide

雄激素受体在乳腺癌中大量表达，最新研究表明雄 激素受体 $(\mathrm{AR})$ 与雌激素受体(ER)比率将会影响乳腺癌 对常规激素疗法(他莫昔芬)的应答. 恩杂鲁胺可阻止雄 激素和雌激素介导的肿瘤生长. 在乳腺癌临床 2 期实验 中，显示了良好的效果. 这也说明对靶点和药理的深刻 理解和认识, 能将许多新药的适应症加以扩展, 在癌症 新药的研究过程中, 这样的例子不胜枚举.

\section{2 舒尼替尼 (Sunitinib) 和 克唑替尼 (Crizotinib)：两个抗癌药物的发明过程}

谈起舒尼替尼的研发，就不能不提及该药发明家和 研发项目主管邓炳初(Cho Tang). 舒尼替尼(Sunitinib, 29)是选择性地靶向抑制多种受体酪氨酸激酶的第一个 抗肿瘤药物 ${ }^{[11]}$. 它能阻断肿瘤生长所需的 VEGF-R2, VEGF-R3 和 VEGF-R1 及血小板衍生生长因子. 克唑替 
尼(Crizotinib, 30)是由辉瑞制药公司研制的一种口服酪 氨酸激酶受体拮抗剂 ${ }^{[12]}$, 该药被批准用于治疗表达异 常的间变性淋巴瘤激酶(ALK)基因的晚期非小细胞肺癌 (NSCLC)患者.<smiles>CCN(CC)CCNC(=O)c1c(C)[nH]c(/C=C2\C(=O)Nc3ccc(F)cc32)c1C</smiles><smiles>C[C@H](Oc1cc(-c2cnn(C3CCNCC3)c2)cnc1N)c1c(Cl)ccc(F)c1Cl</smiles>

舒尼替尼作为多靶点酪氨酸激酶抑制剂，拥有独特 的化学结构, 是使用吲哚-2-酮为骨架的首创新化学实 体(New chemical entity). 从这点来说, 它不同于其它模 仿(me-too)的众多替尼类药物, 这个药物如果是含有嘧 啶(Pyrimidine-based) 杂环为基础 ${ }^{[13]}$, 或是引入喹唑啉 (Quinazoline-based)杂环为基础的酪氨酸激酶抑制剂 ${ }^{[14]}$, 结构创新性就会大打折扣.

舒尼替尼从研发到获批上市，历经了近 12 年光阴 (Scheme 3). 期间经历了至少三个候选化合物的临床试 验，结构修饰、SAR 构效优化、临床方案设计和实施等 工作，凝聚了许多科研人员的辛勤汗水 ${ }^{[15]}$.

舒尼替尼的大规模工业生产也充分体现了有机合 成和工艺创新的威力 (Scheme 4) ${ }^{[16]}$. 取代的吡咯酸 37 经<smiles>Cc1ccc(NC(=O)c2ccc(CN3CCN(C)CC3)cc2)cc1Nc1nccc(-c2cccnc2)n1</smiles><smiles>Cc1nc(Nc2ncc(C(=O)Nc3c(C)cccc3Cl)s2)cc(N2CCN(CCO)CC2)n1</smiles><smiles>COc1cc2c(Nc3ccc(F)c(Cl)c3)ncnc2cc1OCCCN1CCOCC1</smiles><smiles>Cc1cn(-c2cc(NC(=O)c3ccc(C)c(Nc4nccc(-c5cccnc5)n4)c3)cc(C(F)(F)F)c2)cn1</smiles><smiles>C#Cc1cccc(Nc2ncnc3cc(OCCOC)c(OCCOC)cc23)c1</smiles>

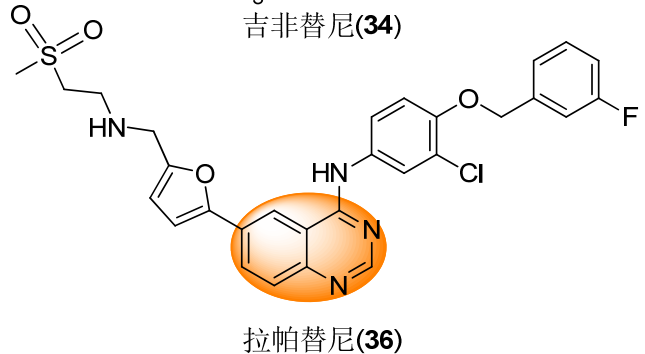

图 1 一些含嘧啶杂环和喹唑啉杂环的抗癌药物

Figure 1 Some pyrimidine-based and quinazoline-based anti-cancer drugs

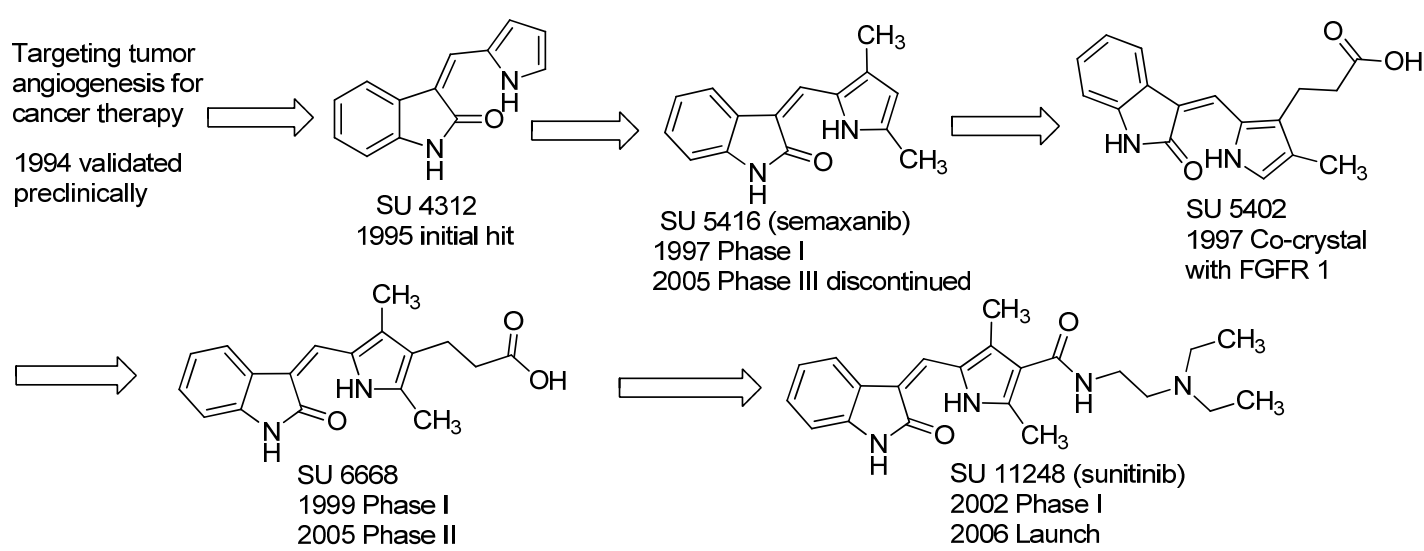

图式 3 舒尼替尼的研发历程

Scheme 3 The chronicle of invention of sunitinib 

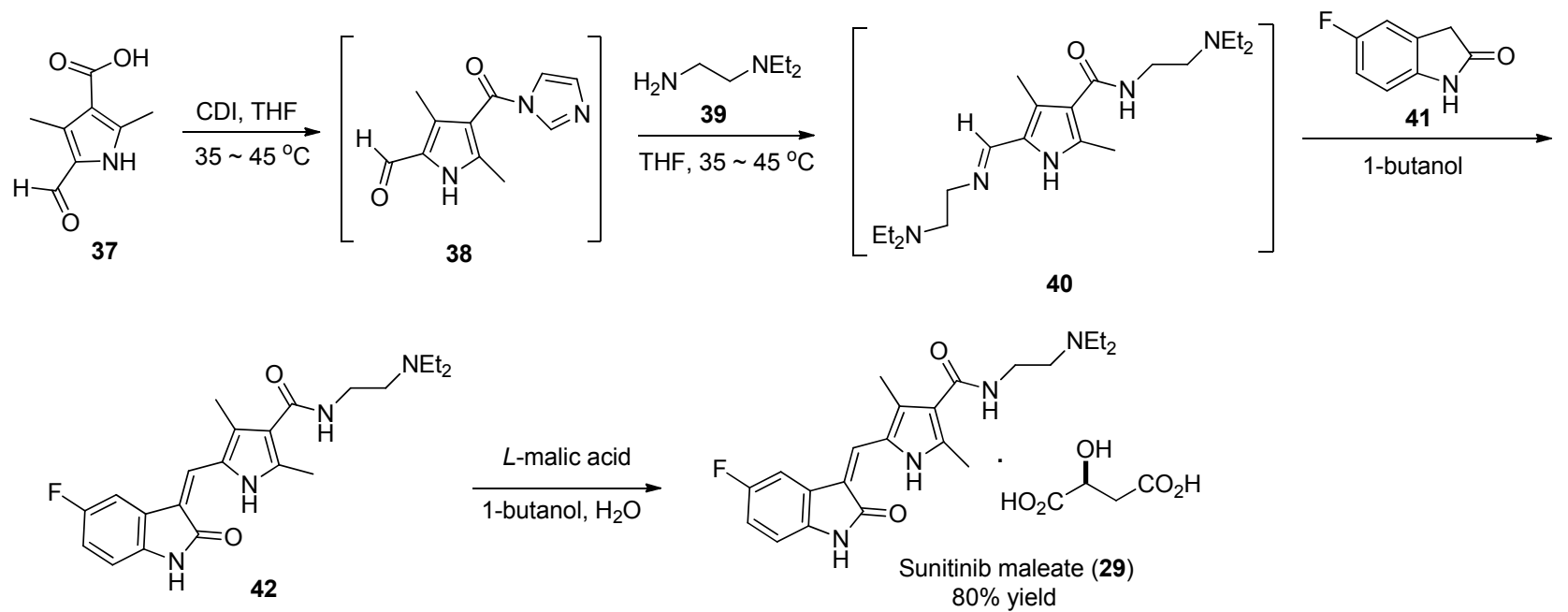

图式 4 舒尼替尼的工业化制备方法

Scheme 4 The scale-up of sunitinib

CDI 活化, 采用过量的 $N, N$-二乙基-乙二胺形成了关键 的亚胺中间体 $\mathbf{4 0}$, 不需要脱保护还原成醛, 亚胺 $\mathbf{4 0}$ 能 和氟代氢化吲哚酮 41 在碱性条件下直接交叉缩合成苏 尼替尼游离碱 42 . 这样经 $L$-苹果酸成盐, 通过四步反应 (避免分离关键中间体 38 和 40), 两步分离纯化的叠缩工 艺, 高产率、高纯度地制备了舒尼替尼的苹果酸盐. 在 药物生产过程中, 有机合成的艺术和技巧发挥了不可替 代的作用 ${ }^{[17]}$.

鉴于四取代吡咯原料的制备成本很高, 辉瑞制药公 司(Pfizer)研发人员探索实施了另一条新颖的合成路 线 ${ }^{[18]}$ : 他们采用活泼的二乙烯酮和 $N, N$-二乙基-乙二胺, 在温和的条件下, 高产率地制备了取代的乙酰乙酰胺, 这样就避开了使用昂贵的酰化试剂 CDI. 同时在洁净的 催化氢化条件下完成了 Knorr 反应. 值得一提的是, 随后 的吡咯环上酫基的引入是通过维尔斯迈尔(Vilsmeier)试 剂 48 来完成的. 形成的亚胺盐 49 和亚胺 40 一样, 有异 曲同工之妙, 不需分离, 也能与氟代吲哚酮 $\mathbf{4 1}$ 直接缩合. 数步反应都进行了很好的工艺条件筛选和优化, 避免了 不必要的纯化, 有效地制备了原料药(API) (Scheme 5).

崔景荣(Jean Cui)小组 ${ }^{[19]}$ 运用靶点蛋白结构为基础 的药物设计理念, 成功地获得了舒尼替尼类似物结合 c-MET 激酶结构域的共晶结构, 并极为合理地设计出 5芳基-3-苄氧基-2-氨基吡啶为骨架的创新药物结构 (Scheme 6), 有效地发明了结构新颖的肺癌新药克唑替 尼(Crizotinib, 50). 其构效关系(SAR)研究归纳出三个阶 段的演变: 一是吡啶 5 位上 $\mathrm{R}$ 基团的引入和笁选; 二是 芳香基团的确立和优化; 三是杂芳环的导入和支链的修 饰. 这些工作, 涉及到大量繁杂快速的合成, 可以看出 有机合成是药物化研究的基础和必备条件.
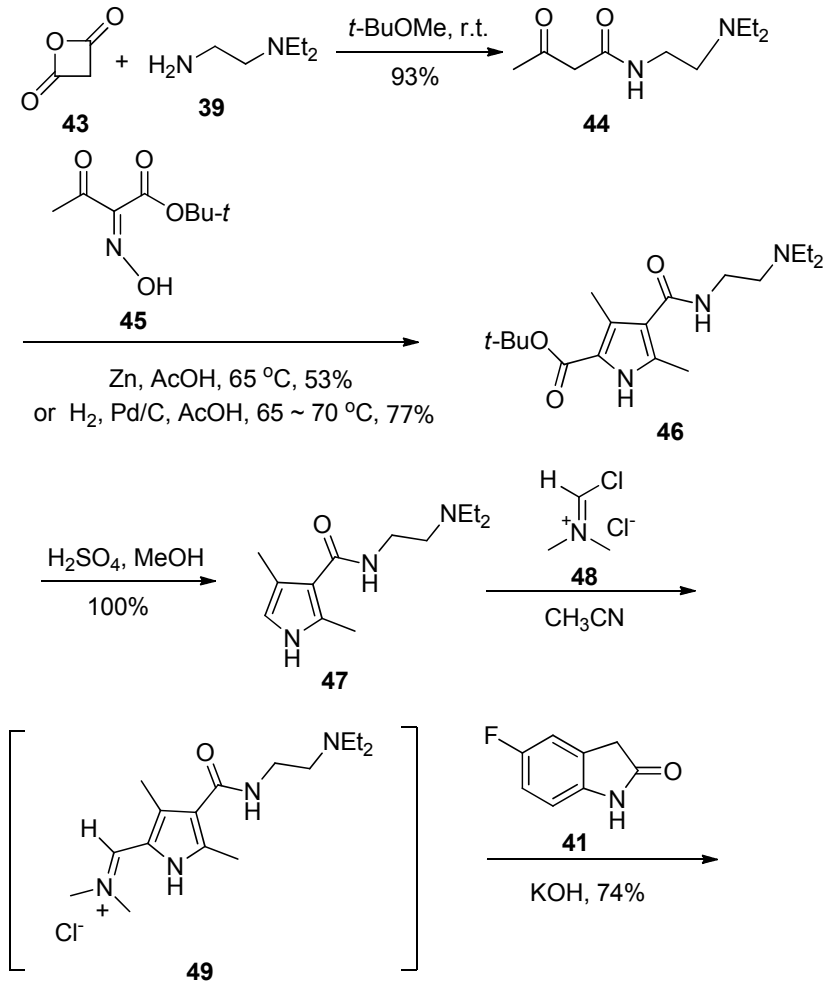

$\mathrm{KOH}, 74 \%$<smiles>CCNCCNC(=O)c1c(C)[nH]c(/C=C2\C(=O)Nc3ccc(F)cc32)c1C</smiles>

Sunitinib (29)

图式 5 舒尼替尼的新合成路线

Scheme 5 The novel synthetic route of sunitinib 


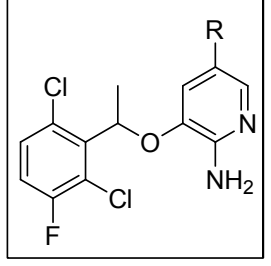

50

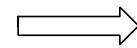

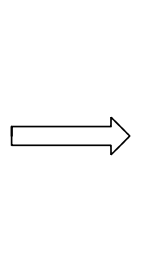

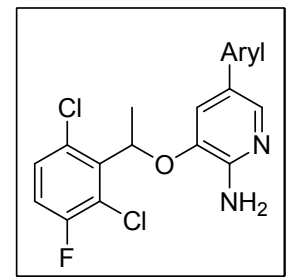

51

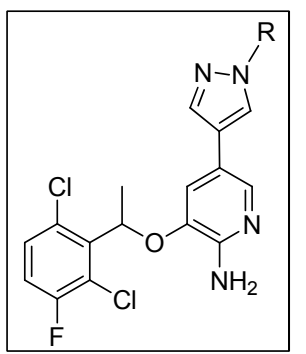

52
图式 6 克唑替尼的逆合成分析

Scheme 6 Retrosynthesis analysis of crizotinib

使用环境友好的绿色化学方法进行手性药物的合 成和生产是近年来许多跨国制药企业重点研究的方

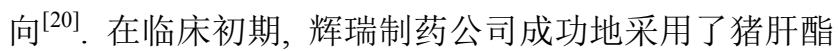
酶对外消旋化的手性醇 54 进行了酯化和酶拆分, 有效 地制备了关键中间体 56 (Scheme 7) ${ }^{[21]}$.

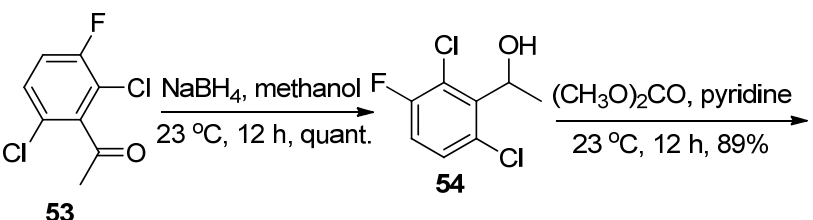<smiles>CC(=O)OC(C)c1c(Cl)ccc(F)c1Cl</smiles>

55<smiles>CC(=O)O[C@@H](C)c1c(Cl)ccc(F)c1Cl</smiles>

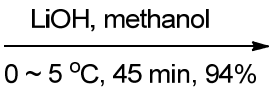

57

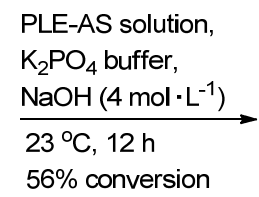
$0 \sim 5^{\circ} \mathrm{C}, 45 \mathrm{~min}, 94 \%$

$97 \%$ ee
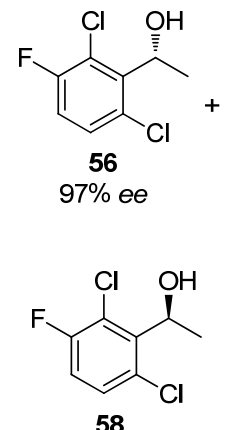

58
图式 7 酶拆分合成手性醇 $\mathbf{5 8}$

Scheme 7 Enzymatic resolution to prepare chiral alcohol $\mathbf{5 8}$

通过使用周其林院士发明的高活性、高选择性的 Ir-Spiro-PAP 手性催化剂 59, 九洲药业制药的科研人员 成功完成了利用不对称催化氢化手段制备手性醇 $(100$ $\mathrm{kg}$ ), ee 值高达 $99.5 \%$, 而转化数 (TON) 数值高达 $100000^{[22]}(\mathrm{Eq} .1)$ ! 值得一提的是, 这一有效方法中似乎
没有发现芳香环有脱氯化氢的副产物。而工业生产中在 催化氢化卤代芳烃时常常有脱卤反应发生，避免和降低 这些副产物往往是工艺的难点之一。

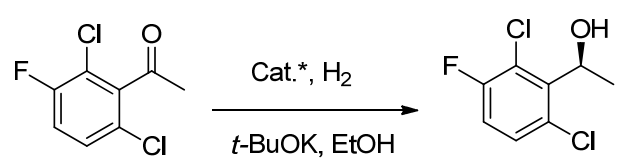

58

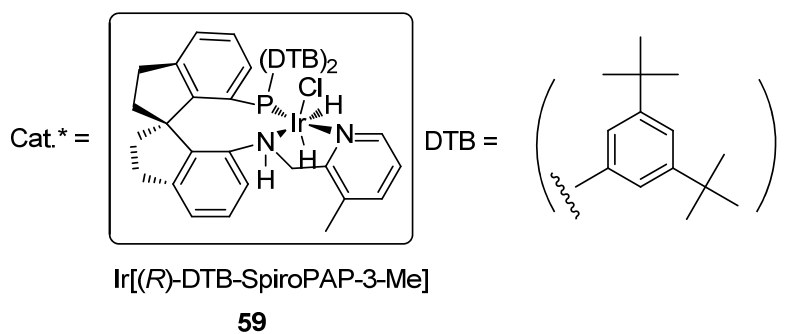

辉瑞制药公司的工艺化学家采用了 Mitsunobu 反应 将手性醇 58 和 3-差欮基-2-硝基吡啶反应形成醚键 ${ }^{[23]}$ ，通 过硝基化合物的还原、溴化反应和 Suzuki 偶联反应等一 系列反应制备了 $100 \mathrm{~kg}$ 的 API 30 (Scheme 8). 应该指出 的是 Mitsunobu 反应和 Wittig 成烯反应一样，使用了大 量的 $\mathrm{Ph}_{3} \mathrm{P}$ 和 $\mathrm{DIAD}$, 造成不少的副产物, 分离纯化都不 容易，我们期待创新的绿色环保合成工艺.

\section{SGLT2 新靶点糖尿病新药 Canagliflozin 和 Dapagliflozin：你追我赶争首创(first-in-class)}

钠一葡萄糖协同转运蛋白(SGLT2)抑制剂能够特异 性抑制肾小球近端小管对滤过葡萄糖重吸收，使过量的 葡萄糖从尿液中排出, 从而降低血糖 ${ }^{[24]}$. 临床研究表明 SGLT2 抑制剂具有良好的药效、安全性和耐受性，是一 种新的治疗 2 型糖尿病高血糖的药物. 在治疗 2 型糖尿 病领域, 百时美施贵宝(Bristol-Myers Squibb)和强生 (Johnson \& Johnson)等药业巨头在 SGLT2 靶点药物研究 上展开了激烈竞争，先后有卡格列净(canagliflozin， 65, 原创为日本的 Mitsubishi 制药, 后转让给强生) ${ }^{[25]}$ 和达 格列净(dapagliflozin, 66, 施贵宝原创) ${ }^{[26]}$ 两个新药(图 2) 上市.

最初药物化学家发现天然的降糖物质根皮苷 67 (Phlorizin)具有降糖作用, 后来将天然的 $O$-酚性配糖体 68(酚苷结构)改造为 $C$-芳基配糖体 69 (C-芳基苷)，体内 代谢更加稳定，具有高度的选择性(SGLT2/SGLT1), 是 更理想的 SGLT2 抑制剂(图 2) ${ }^{[27]}$. 但从合成化学的难度 来说，高度立体选择性地引入 $C$-芳基苷是很具挑战的 工作, 尤其是糖苷化学涉及到许多手性中心和基团的选 择性保护和脱除 ${ }^{[28]}$. 
<smiles>CC(=O)c1c(Cl)ccc(F)c1Cl</smiles>

(1) $\mathrm{NaBH}_{4}$, methanol

(2) $\mathrm{Ac}_{2} \mathrm{O}$, pyridine, $89 \%$ (2 steps)

(3) pig liver esterase solution, $\mathrm{pH} 7$ phosphate buffer, $\mathrm{NaOH}$ then chromatography, $50 \%$ (4) $\mathrm{LiOH}$, methanol, $87 \%$<smiles>CC(O)c1c(Cl)ccc(F)c1Cl</smiles>

58

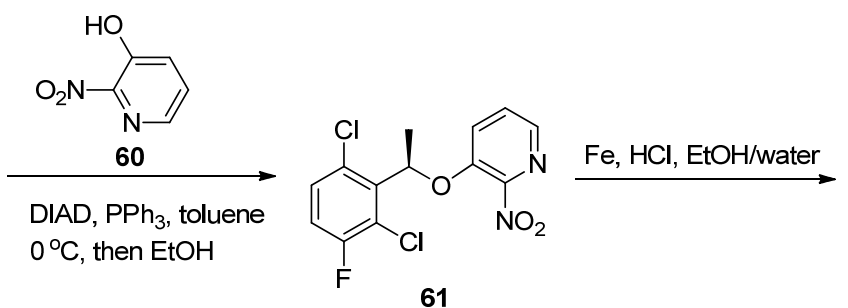

61<smiles>CC(Oc1cccnc1N)c1c(Cl)ccc(F)c1Cl</smiles>

EtOAc, aq. $\mathrm{NaOH}$
then heptane, $62 \%$

then MTBE, reflux $\longrightarrow 62$ a oxalate salt -<smiles></smiles>

$\mathrm{R}=\mathrm{Boc} \longrightarrow$ (1) $\mathrm{HCl}, \mathrm{EtOH} / \mathrm{EtOAc} / \mathrm{CH}_{2} \mathrm{Cl}_{2}$

(2) water

b (3) $\mathrm{NaOH}, \mathrm{THF}$

$\mathrm{R}=\mathrm{H} \longleftarrow$

(4) MeCN/water cryst $75 \%$ 85\%<smiles>C[C@H](Oc1cc(Br)cnc1N)c1c(Cl)ccc(F)c1Cl</smiles>

MTBE, aq. $\mathrm{KOH}$ then heptane, $68 \%$
(1) $\mathrm{PdCl}_{2}$ (dppf) $\cdot \mathrm{CH}_{2} \mathrm{Cl}_{2}, \mathrm{Cs}_{2} \mathrm{CO}_{3}, \mathrm{Bu}_{4} \mathrm{NBr}$ toluene/water, $70{ }^{\circ} \mathrm{C}$

(2) cysteine on silica-alumina, toluene, $60^{\circ} \mathrm{C}$ (3) heptane, $76 \%$ 80\%

图式 8 克唑替尼的合成

Scheme 8 Synthesis of crizotinib<smiles>Cc1ccc(C2O[C@H](CO)[C@@H](O)[C@H](O)[C@H]2O)cc1Cc1ccc(-c2ccc(F)cc2)s1</smiles>

65 , canagliflozin<smiles>CCOc1ccc(Cc2cc([C@@H]3O[C@H](CO)[C@@H](O)[C@H](O)[C@H]3O)ccc2Cl)cc1</smiles>

66, dapagliflozin<smiles>O=C(CCc1ccc(O)cc1)c1c(O)c(O)cc(OC2O[C@H](CO)[C@@H](O)[C@H](O)C2O)c1O</smiles>

67, Phlorizin

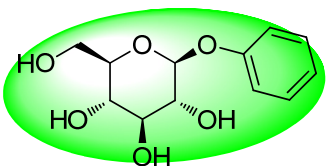

68, O-Aryl glycoside<smiles>OCC1O[C@H](c2ccccc2)[C@H](O)[C@H](O)[C@@H]1O</smiles>

69, C-Aryl glycoside

图 2 一些天然的配糖体和 SGLT2 抑制剂

Figure 2 Some glycosides and SGLT2 inhibitor

百时美施贵宝公司的药物化学家创造性地发明了一种路易斯酸酶促六元环状氧鎓离子的高度立体选择 
性还原，极为有效地制备了乙酰基保护的 1- $C$-芳基 苷 ${ }^{[29]}$. 他们发现反应过程中水的作用极为关键, 它将 $\mathrm{BF}_{3} \mathrm{Et}_{2} \mathrm{O}$ 转化为更强的 Bronsted 酸 $\mathrm{F}_{3} \mathrm{~B}^{-} \mathrm{O}^{+} \mathrm{H}_{2}$, 并加速了 环状氧鎓离子离子中间体的形成, 避免了邻位乙酰氧基 的邻基参与, 使得还原选择性大于 $20 ： 1$. 同时糖羟基 的保护从传统的茮基醚保护转变为乙酰基保护, 不仅降 低了生产成本, 同时也避免了催化氢化脱除茮基时带来 的芳香环上卤素还原 ${ }^{[30]}($ Scheme 9$)$.
氯将氯代溴代苯甲酸 74 转变为相应的酰氯, 随后的 $\mathrm{AlCl}_{3}$ 催化的傅-克酰基化反应，高收率地制备了芳香酮 75. 在三乙基硅烷和三氟化嗍的存在下, 有效和方便地 完成了还原反应. 接下来低温下有机芳香锂试剂对硅醚 化葡萄糖内酯 77 的立体选择性加成和甲基化作用给出 关键的甲基吡喃葡萄糖苷 78. 值得一提的是有效的还 原试剂能方便地除去异头甲氧基，随后的脱保护和重结 晶后处理得到了 Dapagliflozin.

Dapagliflozin 的合成如 Scheme 10 所示, 利用草酰

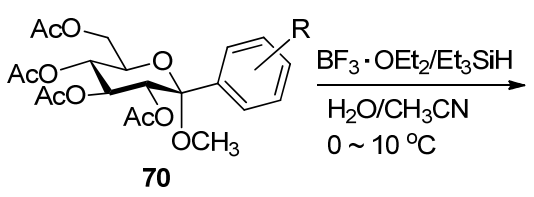<smiles>O=C(O)c1cc(Br)ccc1Cl</smiles>

(1) $(\mathrm{COCl})_{2}$, DCM, DMF $\underset{20}{ }{ }^{\circ} \mathrm{C}, 100 \%$
$0 \sim 5{ }^{\circ} \mathrm{C}, 91 \%$ 74<smiles>CCOc1ccc(C(=O)c2cc(Br)ccc2Cl)cc1</smiles>
$\underset{\mathrm{CH}_{3} \mathrm{CN}, 10^{\circ} \mathrm{C}, 75 \%}{\stackrel{\mathrm{Et}_{3} \mathrm{SiH}, \mathrm{BF}_{3} \cdot \mathrm{OEt}_{2}}{\longrightarrow}}$

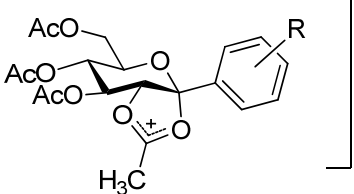

71

图式 9 立体选择性的 $\beta$-C-芳基苷的合成

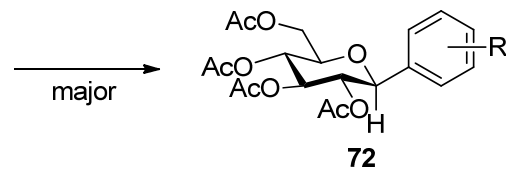

$>20: 1$

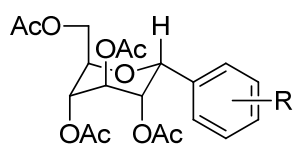

73

Scheme 9 Stereoselective synthesis of $\beta$-C-arylglucoside<smiles>CCOc1ccc(Cc2cc([C@]3(O)O[C@H](CO)[C@@H](O)[C@H](O)[C@H]3O)ccc2Cl)cc1</smiles>

78<smiles>CCOc1ccc(Cc2cc(C3O[C@H](CO)[C@@H](O)[C@H](O)[C@H]3O)ccc2Cl)cc1</smiles>

66, dapagliflozin
(1) $\mathrm{Et}_{3} \mathrm{SiH}, \mathrm{BF}_{3} \cdot \mathrm{OEt}_{2}, \mathrm{DCM}$ $\mathrm{CH}_{3} \mathrm{CN},-10^{\circ} \mathrm{C}$

(2) $\mathrm{Ac}_{2} \mathrm{O}$, pyridine, DMAP, DCM $55 \%$ for 2 steps<smiles>CC(O)C(C)O</smiles><smiles></smiles>

(1) aq. $\mathrm{LiOH}, \mathrm{THF}, \mathrm{H}_{2} \mathrm{O}$

$\mathrm{MeOH}$, r.t., $100 \%$

(2) propanediol, $\mathrm{H}_{2} \mathrm{O}$

图式 10 达格列净的合成

Scheme 10 Synthesis of dapagliflozin 


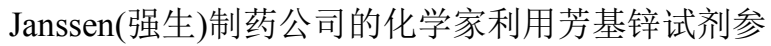
与高度立体选择的和糖苷溴化物交叉偶联反应新方法

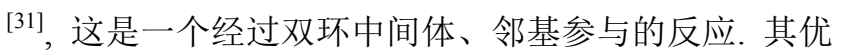
点是避免使用过渡金属催化剂，有效地制备了 Canagliflozin 和 Dapagliflozin (Scheme 11).

Canagliflozin 的合成如 Scheme 12 所示, 利用格氏 试剂 86 与溴代噻吩在镍催化下的 Kumada 偶联反应, 成功制备了取代噻吩 88, 随后通过傅-克酰基化反应、 二甲基硅醚参与的酮 90 的还原反应、和由芳香碘化物 91 制备而产生的芳香锂试剂与溴代糖苷 92 的偶联反应 等，成功制备了 Canagliflozin.

\section{4 丙肝重磅炸弹索非布韦(Sofosbuvir)的突破 性创新：含氟核苷类药物的革命性新成果}

2013 年 12 月美国 FDA 批准 Sofosbuvir (94)上市. 索
非布韦与利巴韦林(Ribavirin)联用，清除了大约 $80 \%$ 感 染者的丙肝病毒. 药理学家 Schinazi 说: “这是在人类历 史上第一次，我们治愈了一种病毒疾病”。<smiles>CC(C)OC(=O)[C@H](C)NP(=O)(OCC1OC(n2ccc(=O)[nH]c2=O)C(F)(F)[C@@H]1O)Oc1ccccc1</smiles>

Sofosbuvir (94)

20 世纪 80 年代初, 科学家发现艾滋病和艾滋病病 毒(HIV)以后, 首先利用具有抗逆转录酶作用的双脱氧 核苷 AZT 即齐多夫定，有效地抑制了艾滋病病毒(HIV) 的复制, 使药物化学家对核苷的功能有了全新的认识, 在全球药物化学界掀起了研制各种类型核苷药物的热

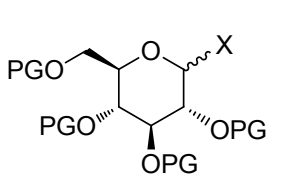

80

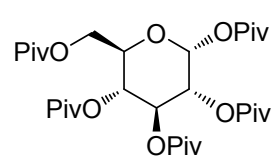

83

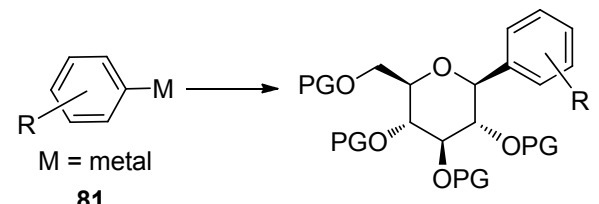

81

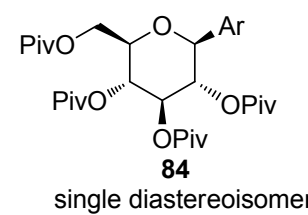

图式 11 有机锌试剂参与的糖苷合成

Scheme 11 C-Glycosylation with arylzinc reagents

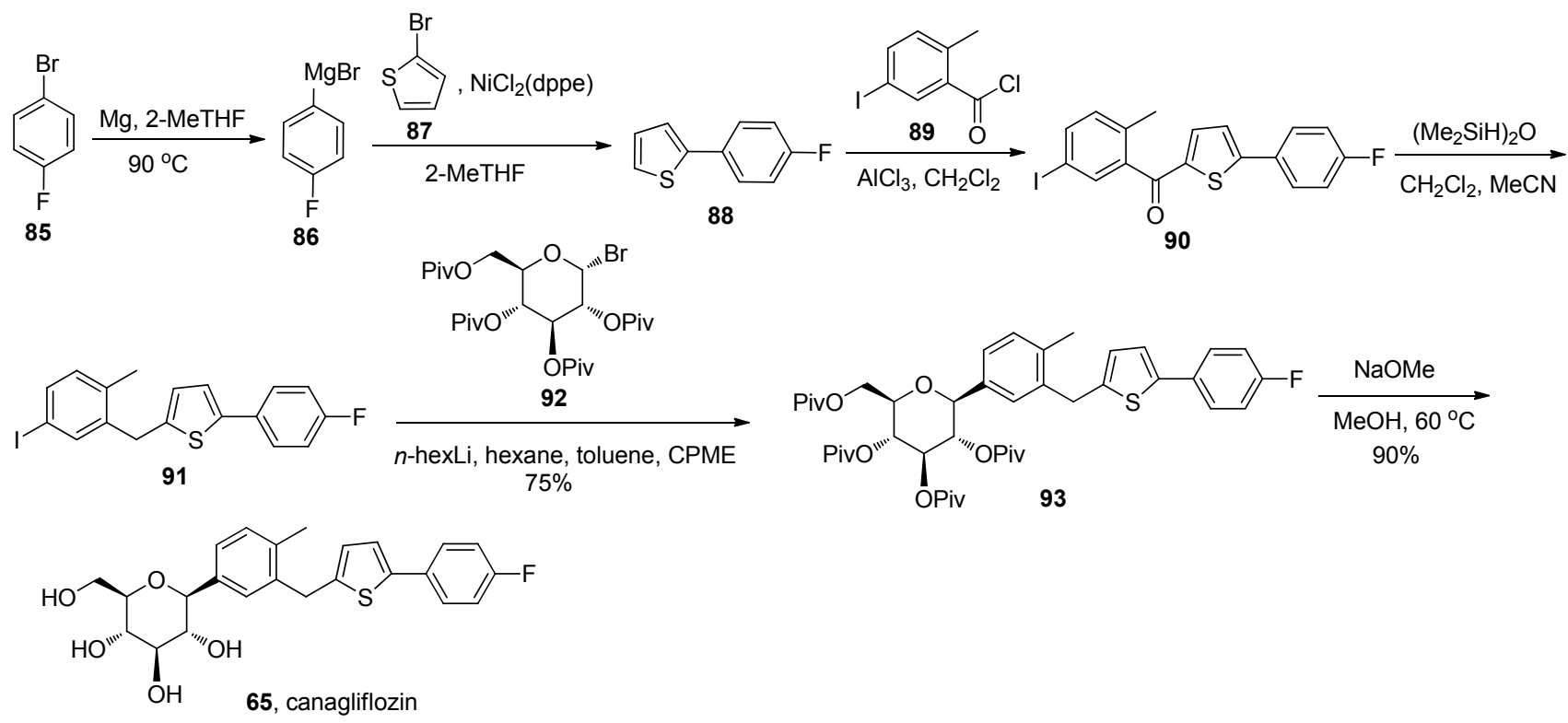

图式 12 卡格列净的合成

Scheme 12 Synthesis of canagliflozin 
潮，近几年篮选非天然的新颖核苷成了研究 $\mathrm{HCV}$ (Hepatitis C virus)药物的热点之一 ${ }^{[32]}$.

一些代表性的含氟药物 ${ }^{[33]}$ 如图 3 所示, 从结构特点 来看, 基本上是将氟原子引入核苷碱基部分, 而核糖部 分基本上不含氟. 在核苷药物中引入氟, 是因为 $\mathrm{C}-\mathrm{F}$ 键有较高的稳定性, 在体内的代谢过程中不易氧化分 解，从而干扰脱氧胸腺核苷酸的生物合成，同时氟代药 物一般具有较好的生物利用度 ${ }^{[34]}$.<smiles>O=c1[nH]cc(F)c(=O)[nH]1</smiles>

Fluorouracil (95)

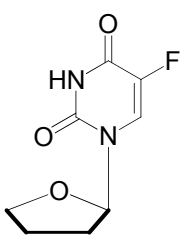

Tegafur (97)

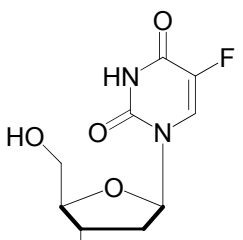

$\mathrm{OH}$

Floxuridine (96)

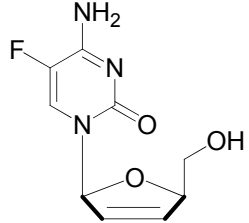

Elvucitabine (98)

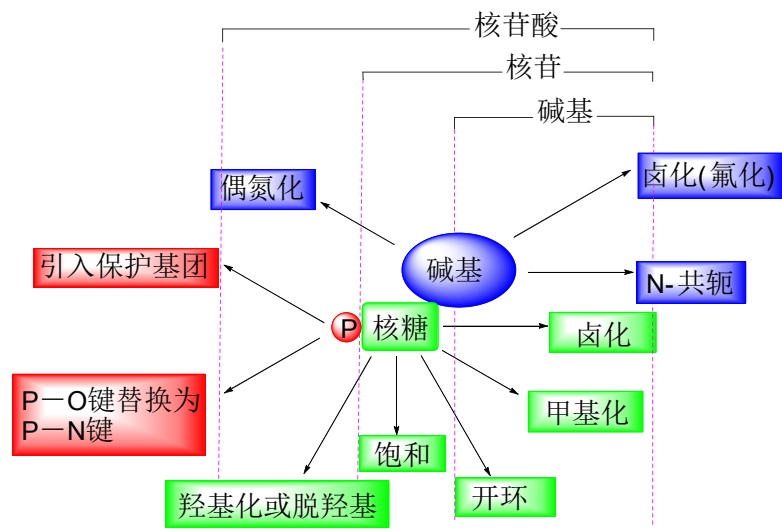

图 3 一些代表性的含氟核苷类药物及核苷和核苷酸结构通 式与化学修饰方式

Figure 3 Some typical fluorine-based nucleside analogues and general structural and chemical modifications of nucleoside and nucleotide analogues

索非布韦是美国新泽西州生物制药公司 Pharmasset 发明的核苷类抗丙肝新药 ${ }^{[35]}$. 2011 年 11 月吉利德制药 (Gilead)以 110 亿美元的高价收购了该公司. 索非布韦 在结构设计方面具有很强新颖性和创造性. 首先, 由于 胞嘧啶核苷 99 (PSI-6130)在其人体内脱氨酶作用下转 变成甲基尿苷 100 (Eq. 2), 因此他们将前药的母核从 99 转移到甲基尿苷 100 , 其次是在戊糖的 2 位上将两个氢 原子分别被甲基和氟原子取代, 增加了药物在代谢过程 中的稳定性, 并且提高了生物利用度. 同时也为了专利
新颖性，打破核苷碱基上引入氟原子的常规，将 $\mathrm{F}$ 原子 转移到了戊糖部分，使戊糖 2 位 $\mathrm{C}$ 成为氟和甲基取代的 手性季碳原子，最后是他们第一次引入了磷酰胺酯前药 设计策略 ${ }^{[36]}$, 最大限度地增加活性核苷酸在细胞内的 浓度，将核苷首次应用于抑制 $\mathrm{HCV}$ 病毒上. 这样的药 物设计是极为合理有效的(Eq. 2).

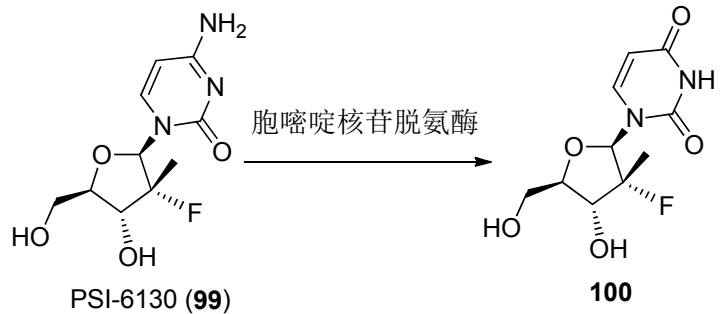

Sofosbuvir 是 $2^{\prime}$-脱氧-2'- $\alpha$-氟- $\beta$-C-甲基尿苷-5'-三磷 酸的前药，经体内酶代谢为活性成分. 通过抑制丙肝病 毒 RNA 聚合酶 NS5B 发挥抗病毒作用. 在 Sofosbuvir 发现之前，人们已考察了多种核苷类似物用于抗丙型病 毒治疗，但活性相对较低. 部分原因是酶促加成第一个 三磷酸基团的速度很慢. Sofosbuvir 的设计避免了这种 缓慢的第一步产生第一个磷酸基团前药的合成过程. 连 接在磷的额外基团暂时掩盖磷酸基团的两个负电荷，促 进该药物迅速进入被感染的细胞(Scheme 13).<smiles>CC(C)OC(=O)C(C)NP(=O)(OCC1OC(n2ccc(=O)[nH]c2=O)C(C)(F)C1O)Oc1ccccc1</smiles>

图式 13 索非布韦的前药(prodrug)化学 Scheme 13 Sofosbuvir prodrug chemistry 
索非布韦的合成如 Scheme 14 所示 ${ }^{[37]}$. 从保护的手 性甘油醛 103 出发, 经 Wittig 成烯反应和随后的高锰酸 钠参与的顺式加成, 得到了关键的光学活性的 2-甲基2,3-二羟基戊酸乙酯(105), 经过亚磺酰氯和次氯酸钠的 氧化作用, 成功制备了手性的磺酸内酯 106. 随后的 $\mathrm{TEA} \cdot 3 \mathrm{HF}$ 处理, 顺利地进行了氟代反应, 得到了手性含 氟环戊内酯 107. 随后经羟基保护、内酯 108 还原成半 缩醛和氯化反应以及关键的连接胞嘧啶核苷碱基，成功 地制备了前药母核 100. 随后与磷酰胺酯作用得到了索 非布韦(Scheme 14).

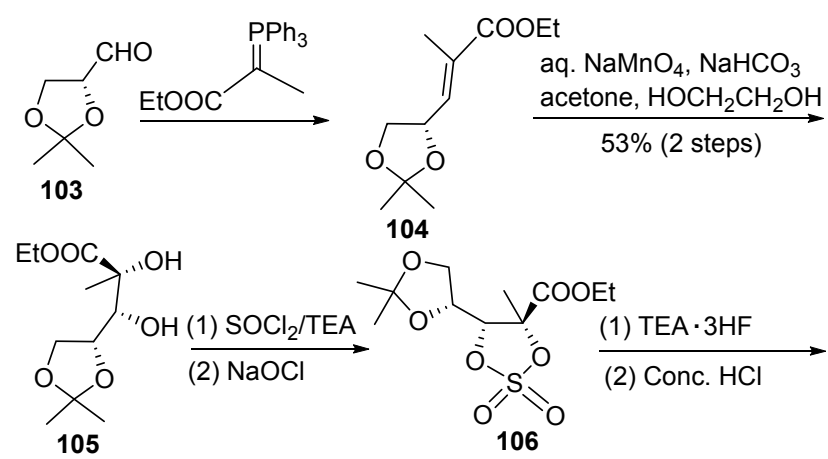

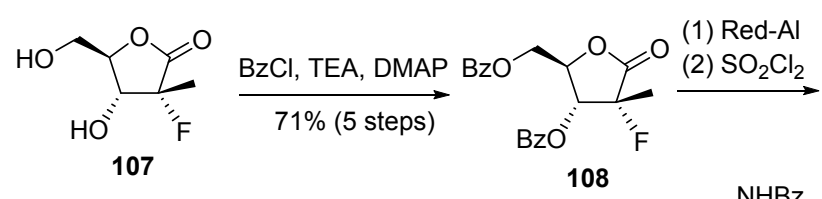

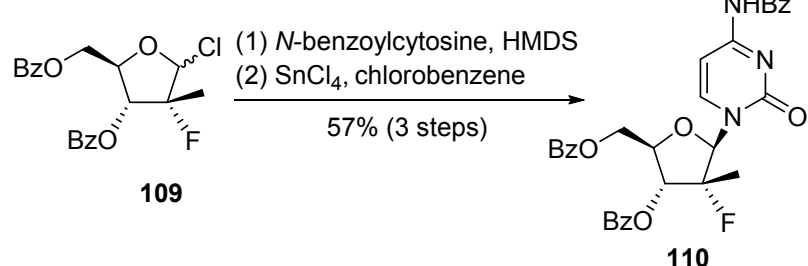

(1) $70 \%$ aq. $\mathrm{AcOH}$ (2) $\mathrm{NH}_{3} / \mathrm{MeOH}$ $78 \%$ (2 steps) $\overrightarrow{\mathrm{HO}}$<smiles>CC(C)OC(=O)C(C)NP(=O)(O)Oc1c(F)c(F)c(F)c(F)c1F</smiles>

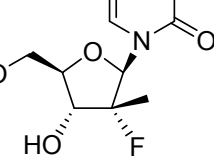

$\mathrm{gCl}, \mathrm{THF}$ 100<smiles>CC(C)OC(=O)C(C)NP(=O)(OCC1OC2C(=O)NC(=O)C=CN2[C@@]1(C)F)Oc1ccccc1</smiles>

Sofosbuvir (94)

图式 14 索非布韦的合成 Scheme 14 Synthesis of sofosbuvir
Ross 等 ${ }^{[38]}$ 在索非布韦前药的合成中, 成功引入了 含有苯酚、五氟苯酚和光学活性氨基酸组成的磷酰胺酯 化新试剂, 进而通过选择性的亲核取代, 有效和选择性 地制备了单一的非对映异构体，从而避免了一般在磷酰 胺酯前药中出现非对映异构体混合物的问题(Eq. 3).<smiles>CC(C)OC(=O)[C@H](C)NP(=O)(Oc1ccccc1)Oc1c(F)c(F)c(F)c(F)c1OP(=O)(N[C@@H](C)C(=O)OC(C)C)Oc1ccccc1</smiles>

普林斯顿大学的 MacMillan 小组 ${ }^{[39]}$ 最近报道了手性 氟代戊糖新的合成方法, 成功制备了 PSI-6130. 其关键 反应是使用 $\mathrm{TiCl}_{2}(\mathrm{OPr}-i)_{2}$ 作为路易斯酸进行 Mukaiyama aldol 偶联反应，以 $79 \%$ 的收率制备了单一的非对映异 构体中间体，极为有效地引入含氟的手性季碳，经过还 原条件下的脱除保护基 OTMP，内酯化和重结晶得到 $99 \%$ ee 值的氟代戊糖(Scheme 15).

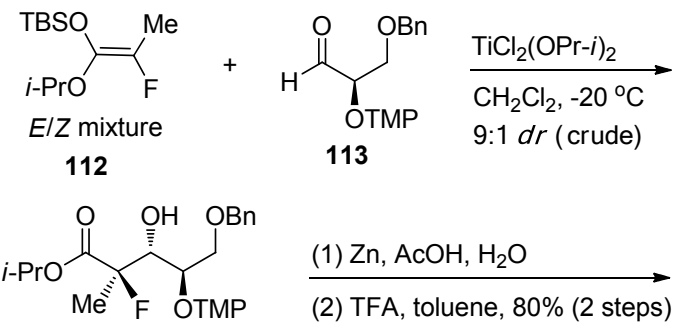

$79 \%,>20: 1 d r$ isolated

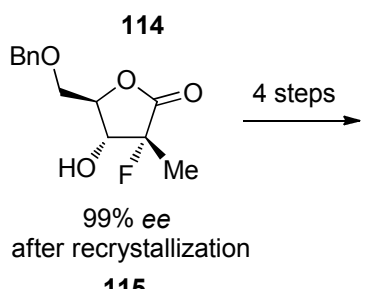

115

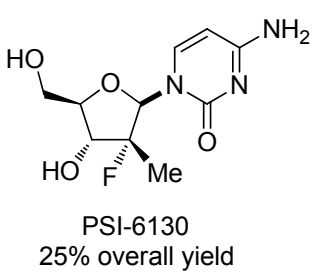

116
图式 15 PSI-6130 对映选择性合成

Scheme 15 Enantioselective synthesis of PSI-6130 


\section{5 风湿性关节炎 Tofacitinib 和癌症新药 Ruxolitinib (鲁索替尼): 源于 JAK 新靶点的 2 个新药}

托法替尼(Tofacitinib, 117, CP-690550)是辉瑞制药公 司研发的一种新型口服 JAK (Janus kinase)通路抑制剂. 与当前多数其他类风湿性关节炎治疗药物主要作用于细 胞外靶点不同的是, 托法替尼以细胞内信号转导通路为 靶点，作用于细胞因子网络的核心部分. 托法替尼对 JAK3 的抑制强度是对 JAK 1 及 JAK2 的 5 100 倍. 托法 替尼是用于类风湿性关节炎治疗的首创药物.

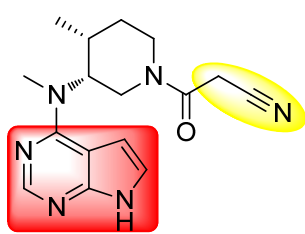

Tofacitinib (117)

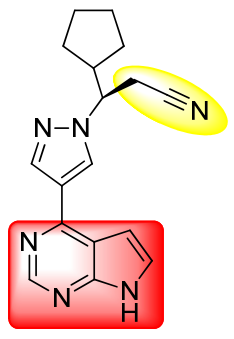

Ruxolitinib (118)
从辉瑞制药公司公布的托法替尼的合成路线 (Scheme 16)来看, 其关键和精美之处是用取代吡啶成 盐和 $\mathrm{NaBH}_{4}$ 作用下 120 转化为四取代的烯烃 121, 利用 有效的手性金属催化剂和 LDPTT 进行拆解，得到了极 为关键的手性化合物 122 ! 值得一提的是，最后一步引 入氧代乙酰基, 辉瑞制药公司工艺研发人员首创了温和 条件下 DBU 催化的直接氨解㲵乙酸酯 ${ }^{[00]}$ (Scheme 17), 该方法简单有效，避免了腈乙酸的活化和高温反应.

骨髓纤维化是一种疾病，导致制造血细胞器官如肝 和脾骨髓被瘚痕组织替代. 被称为 JAK1 和 JAK2 (Janus 相关激酶)的抑制酶涉及调节血液和免疫学功能, JAK 1 和 2 调节障碍伴随骨髓纤维化. 美国 FDA 于 2011 年 11 月批准 Ruxolitinib(鲁索替尼)上市. 这是特异性治疗骨 髓纤维化骨髓病患者的第一个药物 ${ }^{[41]}$. 在合成 Ruxolitinib 的反应中, 科研小组成功利用了有机催化的 Aza-Michael 反应制备了 Ruxolitinib ${ }^{[42]}$ ，产率高达 84\%, $e e$ 值为 $93 \%$. 美中不足的是手性催化剂 $\mathbf{1 3 4}$ 的结构较为 复杂, 且催化剂用量较高(Scheme 18).

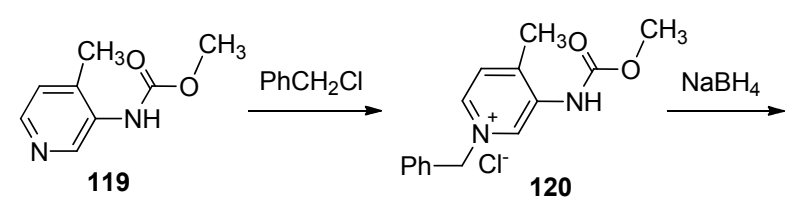<smiles>COC(=O)NC1=C(C)CCN(Cc2ccccc2)C1</smiles>

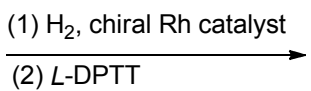<smiles>CNC1CN(Cc2ccccc2)CCC1C</smiles>

122<smiles>CC(C)[Y19]1N=C(Cl)N=C(Cl)c2cc[nH]c21</smiles><smiles>CC1CCNCC1N(C)c1ncnc2[nH]ccc12</smiles>

125<smiles>CCOC(=O)CC#N</smiles>

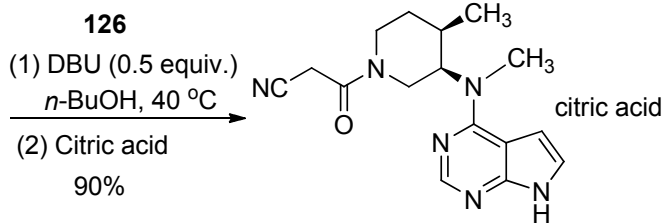

Tofacitinib (117)

图式 16 托法替尼的合成

Scheme 16 Synthesis of tofacitinib

Proposed catalytic cycle

$\mathrm{R}^{3} \mathrm{OH}+$
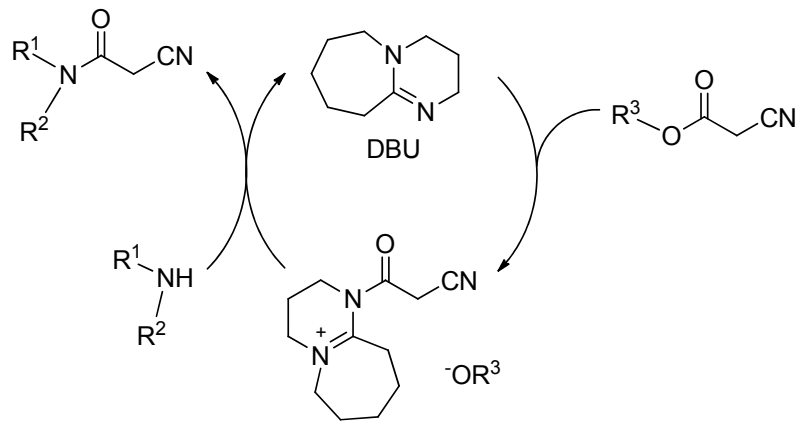

图式 17 采用 DBU 进行酰胺化的催化成环

Scheme 17 Catalytic cycle for amidation using DBU 


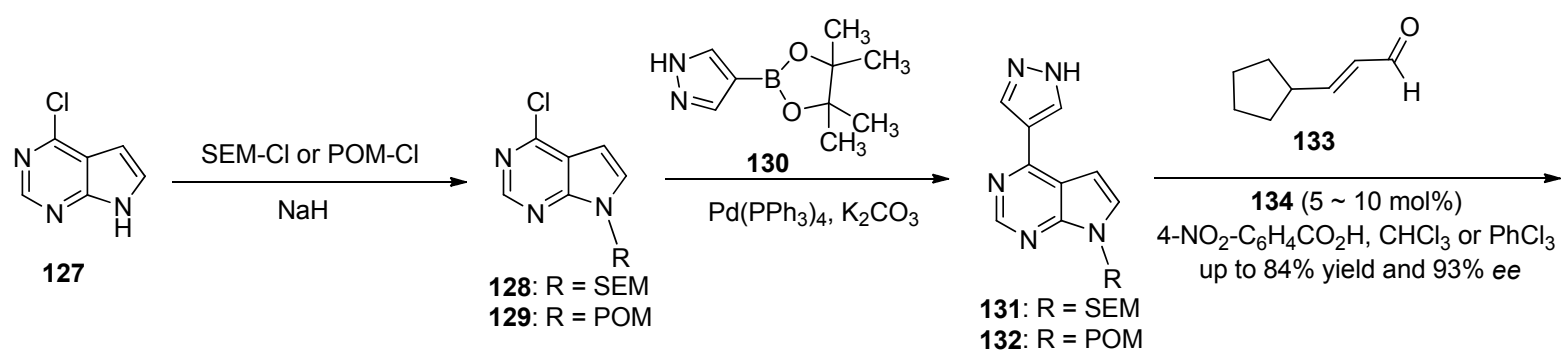<smiles>[R]n1ccc2c(-c3cnn([C@H](CC(=O)C4CCCC4)C4CCCC4)c3)ncnc21</smiles>

135: $R=$ SEM 136: $R=P O M$<smiles>CC[Si](CC)(CC)OC(c1cc(C(F)(F)F)cc(C(F)(F)F)c1)(c1cc(C(F)(F)F)cc(C(F)(F)F)c1)C1CCCN1</smiles><smiles>CCC(C)n1cc(-c2ncnc3c2ccn3F)cn1</smiles>

137: $R=S E M$ 138: $R=P O M$<smiles>N#CCC(C1CCC(C(=N)O)CC1)n1cc(-c2ncnc3[nH]ccc23)cn1</smiles>

Ruxolitinib (118)

134

图式 18 鲁索替尼(Ruxolitinib)的合成

Scheme 18 Synthesis of ruxolitinib

\section{6 抗菌的利奈唑胺(Linezolid)、Tedizolid 以及 抗血栓的利伐沙班(Rivaroxaban): 源于噁唑烷 酮的三个新药}

手性噁唑烷酮, 尤其是芳基取代的 Evans 手性助剂 (又称手性辅基)在不对称合成领域应用广泛 ${ }^{[43]}$, 但这种 常见手性化合物近 20 年来却成为了新药设计的药效基 才, 在此基础上人们成功开发了新型抗菌、抗血栓新 药 ${ }^{[44]}$.
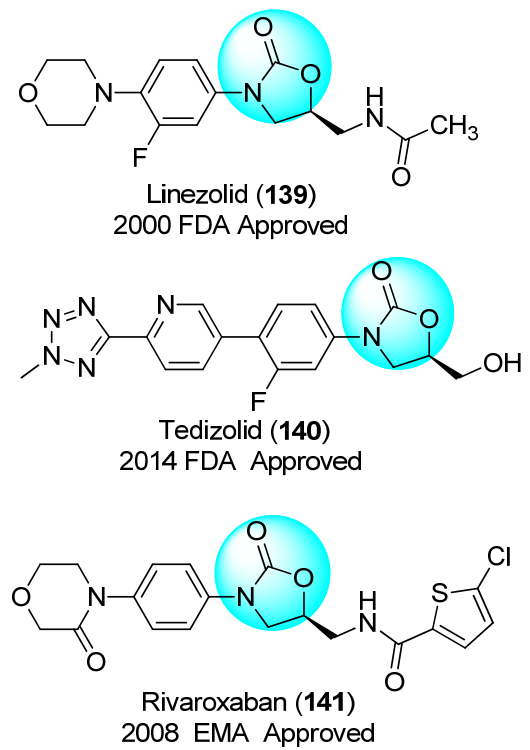

利奈唑胺是噁唑烷酮类(Oxazolidinones)抗菌药. 对 甲氧西林耐药金葡菌和凝固酶阴性葡萄球菌具良好的 抗菌作用. 1978 年的杜邦公司专利首次报道噁唑烷酮的 抗菌作用. 开发的该类两个化合物 Dup-721 (143)和 Dup-105 (144)进入临床实验, 但是都由于毒性问题而放 弃. Upjohn 的药物化学家们在此基础上继续研发, 开展 一系列 SAR 构效关系的研究 ${ }^{[45]}$, 终于在 2000 年研发出 了理想的药物分子-利奈唑胺(Scheme 19). 它是近几十 年来首个非天然来源的新型抗菌小分子药物, 解决了细 菌耐药性问题.<smiles>CC(=O)NC[C@H]1CN(c2ccc(S(C)=O)cc2)C(=O)O1</smiles>

DuP-105 (142)<smiles>CC(=O)NC[C@H]1CN(c2ccc(C(C)=O)cc2)C(=O)O1</smiles>

DuP-721 (143)
值得一提的是, 3,4-二氟代硝基苯 144 中的 4 位氟取 代基非常活泼, 极易被吗啡啉选择性地氨解, 在利奈唑 胺的合成中, 手性的噁唑烷酮 149 是由氯代丙二醇和取 代的氨基甲酸酯 147 缩合而得的(Scheme 19).

2003 年 Barbachyn 等 ${ }^{[46]}$ 在总结利奈唑胺的构效关系 研究时指出: 手性啞唑烷酮结构是化合物抗菌活性所必 须的药效基，而 $\mathrm{C}(5)$ 上的乙酰氨甲基对抗菌活性非常重 


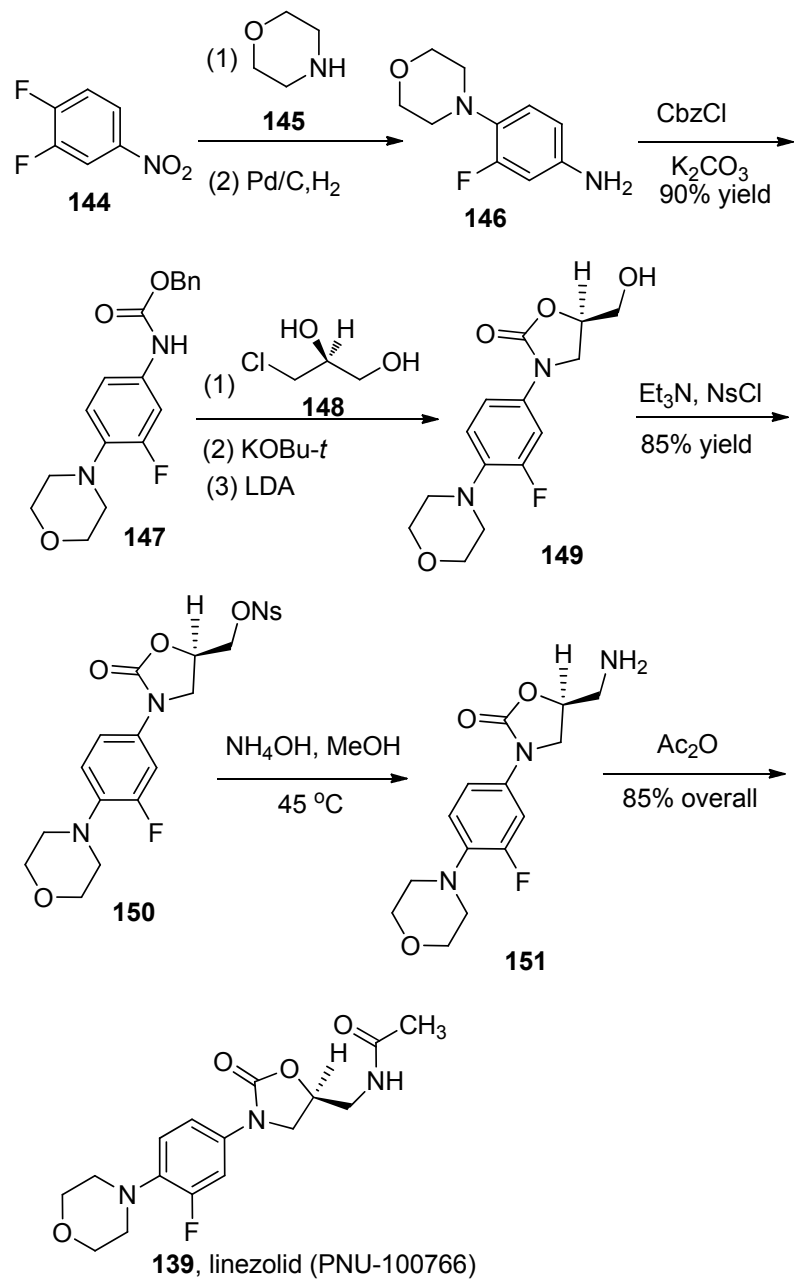

图式 19 利奈唑胺的合成

Scheme 19 Synthesis of linezolid

要, 苯环上引入氟原子改善了药物在水中的溶解度. 而 吗啉环取代哌嗪杂环则提高了化合物的安全性. 应该说 选择利奈唑胺作为临床药物是综合考虑药物毒性、抗菌 活性、药物动力学和药代、水溶性以及其它相关性质的 结果, 有关利奈唑胺构效关系(SAR)如图 4 所示 ${ }^{[47]}$.

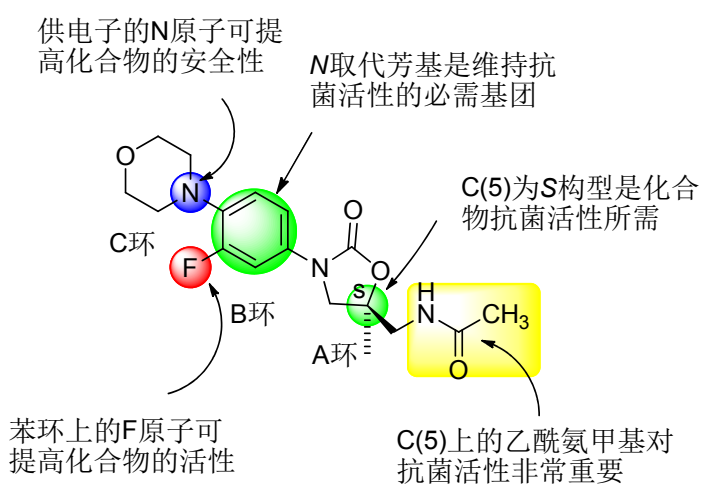

图 4 噁唑烷酮类药物构效关系

Figure 4 Structure-activity relationships of oxazolidinones

在经历了近 14 年的沉寂之后, 2014 年美国 FDA 批
准了另一个含噁唑烷酮的抗菌新药，Tedizolid(特地唑 胺)(图 5) ${ }^{[48]}$. 从结构的演化和改进来看 ${ }^{[49]}$, 有三点非常 值得强调, 一是在原有 $\mathrm{A}$ 环、 $\mathrm{B}$ 环、 $\mathrm{C}$ 环和 $\mathrm{C}(5)$ 支链的 基础上, 药物化学家加上了含四唑或三唑的 $\mathrm{D}$ 环和支 链; 二是在 $\mathrm{C}(5)$ 支链上第一次引入磷酸酯前药; 三是该 药的原创是韩国的 Dong-A 制药(后授权给美国的 Trius 制药), 希望有一天许多新药的原创也来自中国.

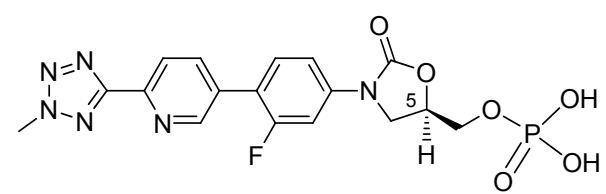

Tedizolid phosphate (torezolid phosphate, TR-701, DA-7218) Trius/Dong-A

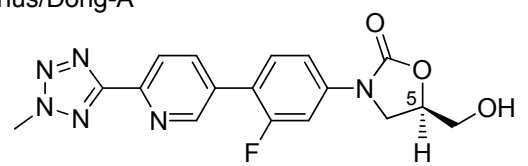

140, Tedizolid (TR-700, torezolid, DA-7157) Trius/Dong-A
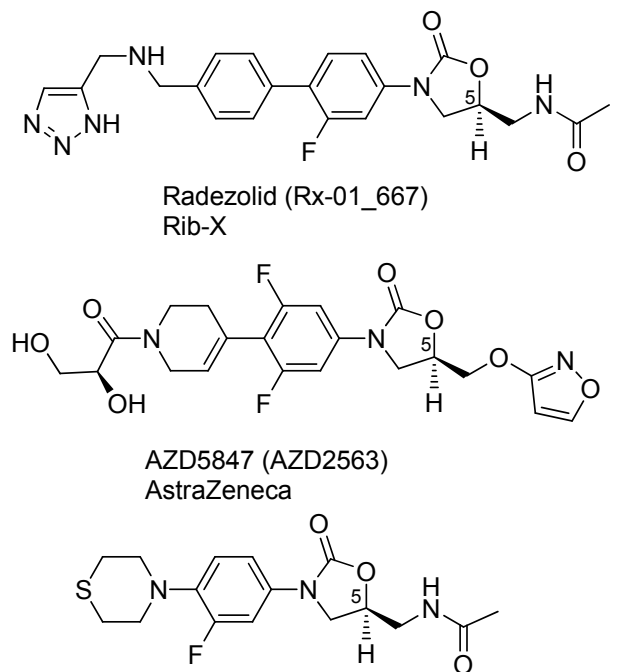

Sutezolid (PNU-100480, PF-02341272) Pfizer/Pharmacia \& Upjohn

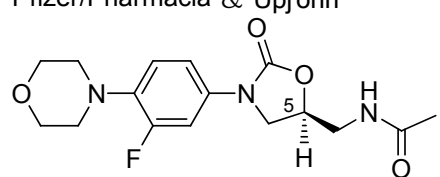

139, Linezolid (PNU-100766) Pfizer/Pharmacia \& Upjohn

$\begin{gathered}\text { D-ring or } \\ \text { side chain }\end{gathered}$ C-ring B-ring A-ring
$\begin{gathered}\mathrm{C}-5 \\ \text { side chain }\end{gathered}$

图 5 利奈唑胺和其它噁唑烷酮类药物发展历程(1978～2014) Figure 5 The chronicle of invention of linezolid and other oxazolidinones

拜耳制药(Bayer)药物化学家另辟蹊径将噁唑烷酮 化学结构引入抗血栓治疗领域 ${ }^{[50]}$. 成功开发了新药利 伐沙班. 其中噁唑烷酮的合成应用了便宜易得的手性环 氧化物 153 , 通过氨解开环和 CDI 作用下的成环作用, 
高产率地制备了关键中间体 155 (Scheme 20). 当然最佳 方法仍然是使用环氧氯丙烷为手性源. 利奈唑胺中噁唑 烷酮 139 的合成则与上述方法有些不同(Scheme 21), 它 采用手性的氯代氨基丙醇 160 为原料, 避免了采用氯代 丙二醇(148)构造啞唑烷酮的缺陷, 即消除了将差基转 变为氨基的三步反应(Scheme 19), 反应更趋合理.
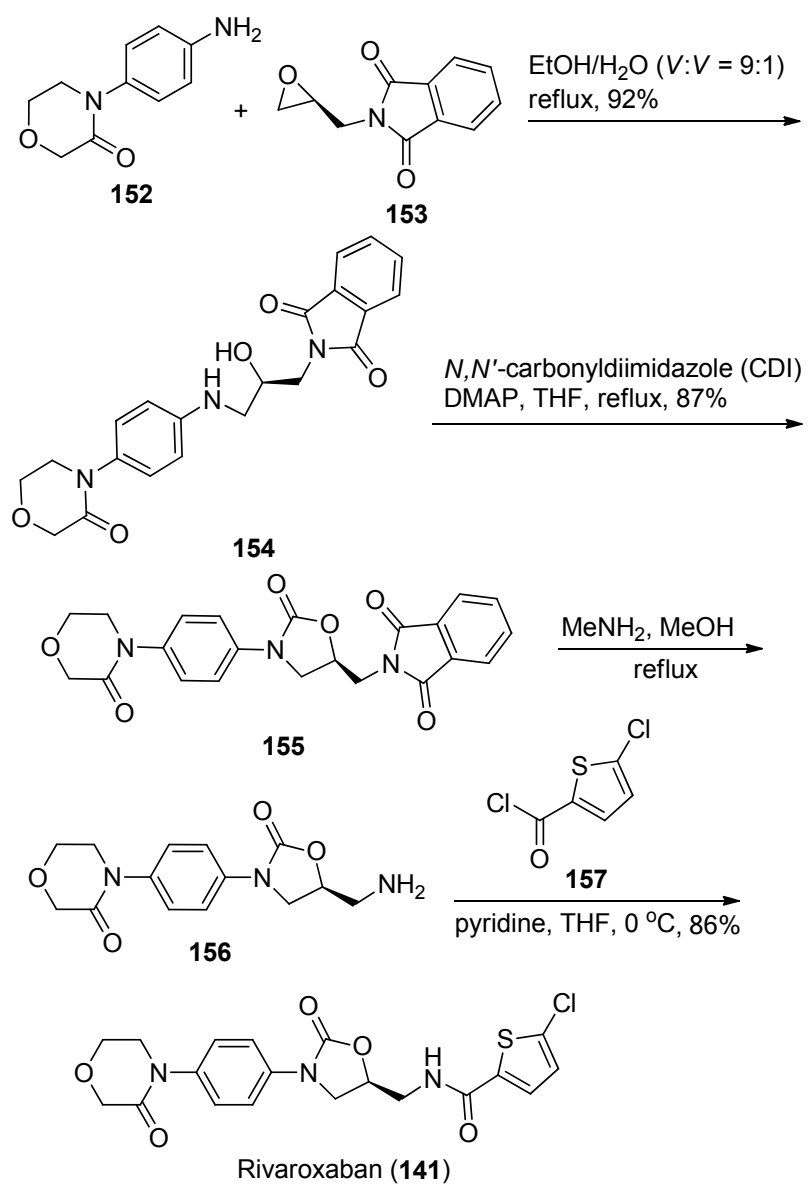

图式 20 利伐沙班的合成

Scheme 20 Synthesis of rivaroxaban
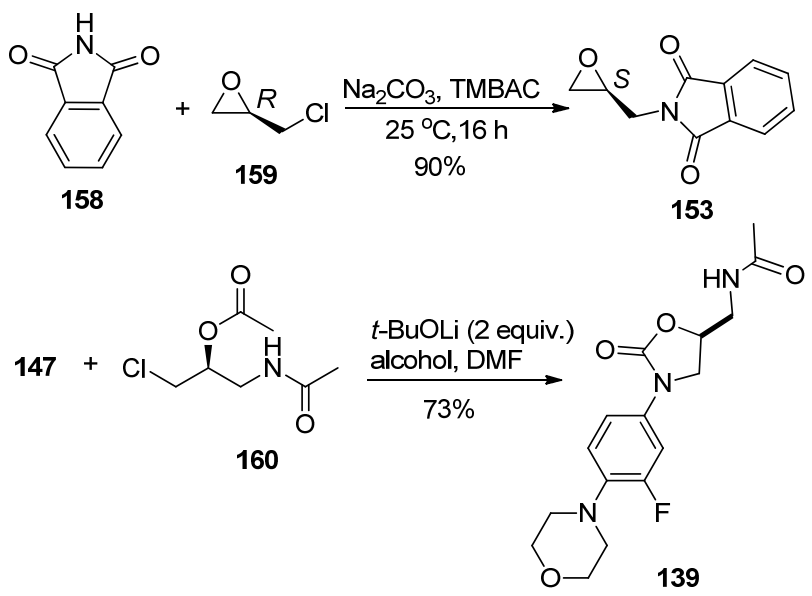

图式 21 利奈唑胺工艺的改善

Scheme 21 The process improvement of linezolid
7 Simeprevir (TMC435)和临床三期的 NS3/ 4A 蛋白酶抑制剂及 NS5A/5B 病毒抑制剂: HCV 病毒 “魔高一尺”，药物化学家 “道高一丈”

丙型肝炎是一种复杂的疾病，基因 1 型丙型肝炎尤 其难以治愈. 长期发展演化为对肝脏造成严重的损害, 包括肝硬化和肝癌. 丙型肝炎病毒(Hepatitis C Virus, HCV) NS3/4A 丝氨酸蛋白酶和 NS5A/5B RNA 依赖的 RNA 聚合酶是病毒蛋白前体加工成熟和复制过程中十 分重要的两个酶, 是抗 $\mathrm{HCV}$ 治疗的理想靶点 ${ }^{[51]}$. 近年

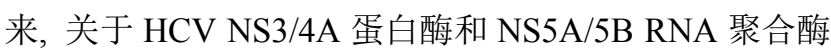
抑制剂的研究是抗 HCV 研究最为热门的方向 ${ }^{[52]}$.

第一代 NS3/4A 抑制剂药物是 Vertex 公司的特拉匹 韦(Telaprevir, 161)和 Merck 公司的波普瑞韦(Boceprevir, 162). 两者都是含有环并脯氨酸骨架的多肽类蛋白酶抑 制剂 ${ }^{[53,54]}$, 其化学结构相对复杂. 特拉匹韦和波普瑞韦 是直接作用抗病毒新药，但是存在明显不足，首先是服 用不便，并且剂量大，其次是存在明显副作用. 为此开 发第二代 NS3/4A 药物应运而生.<smiles>CCCC(NC(=O)C1C2CCCC2CN1C(=O)[C@@H](NC(=O)C(NC(=O)c1cnccn1)C1CCCCC1)C(C)(C)C)C(=O)C(=O)NC1CC1</smiles>

Telaprevir (161)<smiles>CC1C2C(C(=O)NC(CC3CCC3)C(=O)C(N)=O)[C@H]2CN1C(=O)[C@@H](NC(=O)NC(C)(C)C)C(C)(C)C</smiles>

Boceprevir (162)

从第二代 NS3/4A 抑制剂药物的结构来看, 其复杂 程度和合成挑战更加突出. 研发人员在保留脯氨酸骨架 的同时, 引入了极为关键的 $(1 R, 2 S)$-1-氨基-2-乙烯基环 丙基羧酸的骨架，几个研发小组还加入了大环内酰胺的 单元和药效基, 巧妙避开了专利问题. 图 6 是第二代 $\mathrm{NS} 3 / 4 \mathrm{~A}$ 抑制剂药物.

Simeprevir (169, TMC435) 是一种 NS3/4A 蛋白酶抑 制剂，由杨森制药和 Medivir AB 制药联合开发(Eq. 4), 用于基因 1 型慢性丙型肝炎患者代偿性肝脏疾病的治 疗, 活性和选择性大大提高, 只需口服一次. Simeprevir 被认为通过阻断使 $\mathrm{HCV}$ 在宿主细胞内生存和复制的蛋 白酶而发挥作用. 


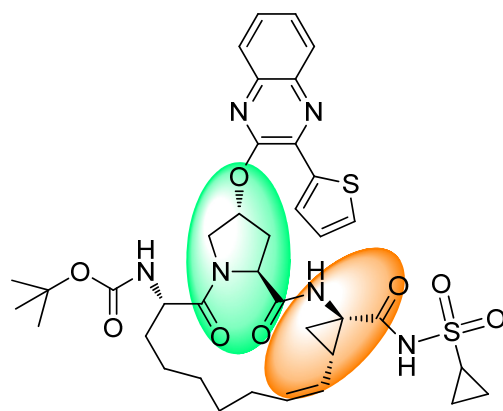

163, ABT-450/r (Abbott/Enanta)

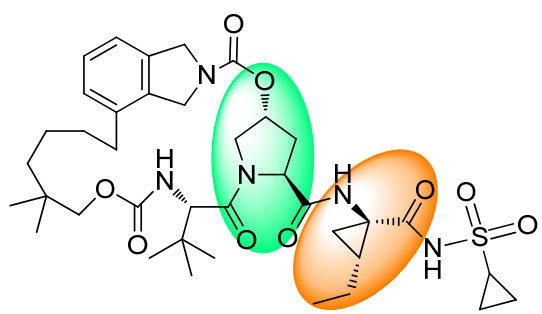

166, Vaniprevir (Merck Jpn)

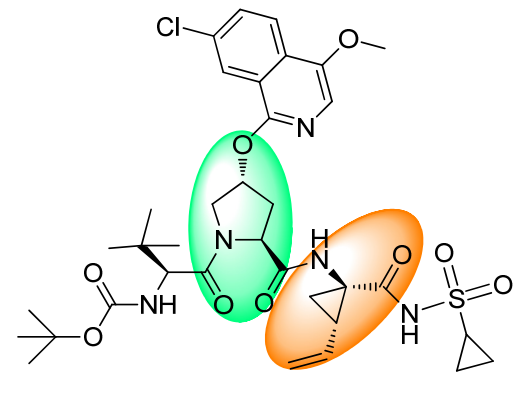

164, Asunaprevir (BMS)

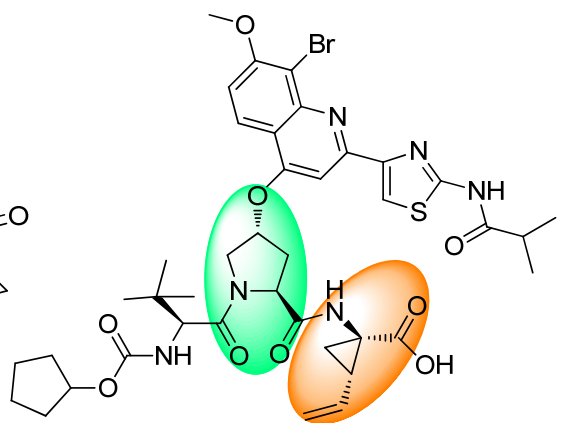

167, Faldaprevir (BI)

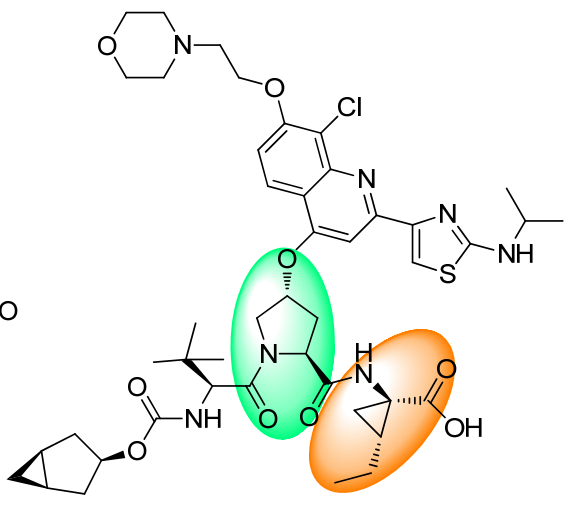

165, Vedroprevir (Gilead)

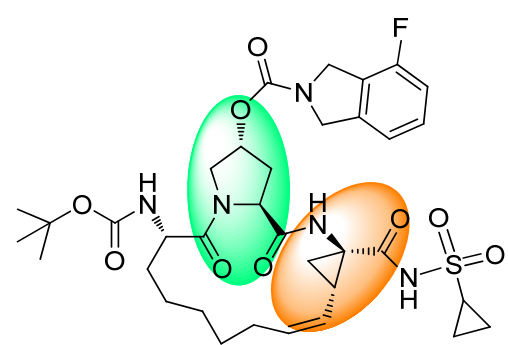

168, Danoprevir (Roche)

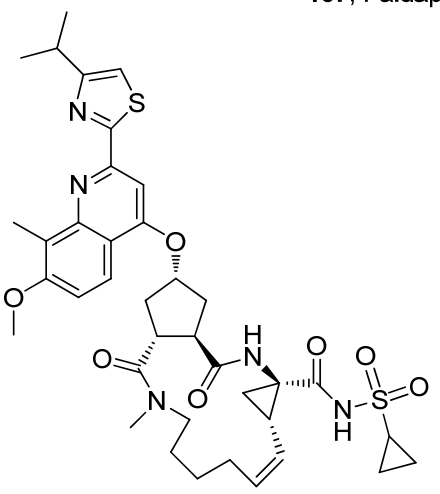

169, Simeprevir(Janssen \& Medivir)

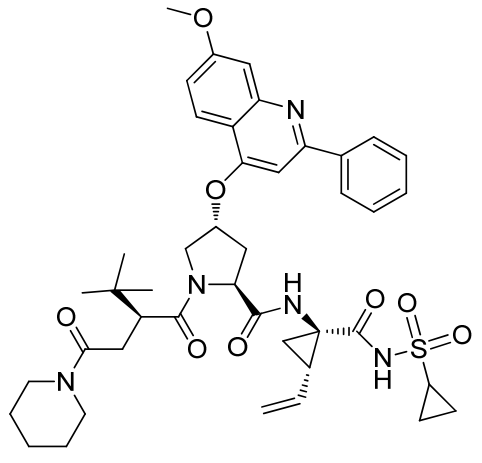

170, Sovaprevir (Achillion)

图 6 一些代表性的临床 $2 、 3$ 期 NS3/4A 蛋白酶抑制剂药物

Figure 6 HCV NS3/4A inhibitors in late-stage clinical development

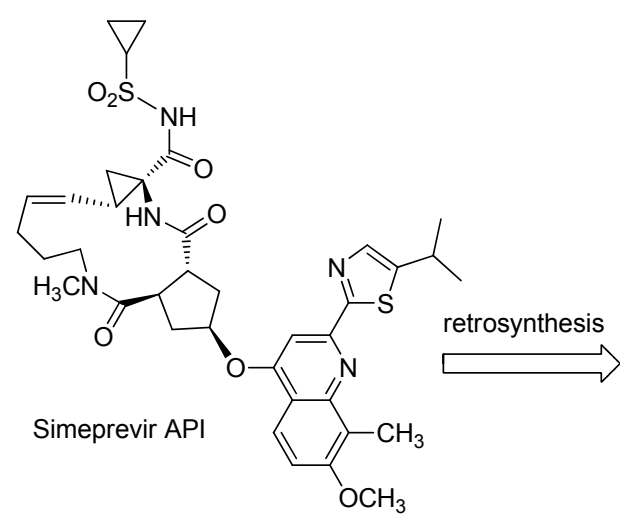

169, Simeprevir

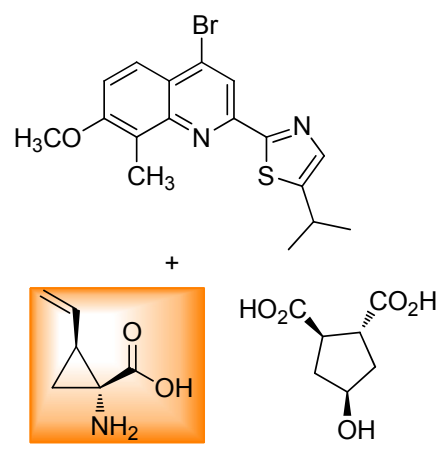

Critical Raw Materials 
药物合成的艺术也体现在设计上的创新, Rosenquist 等 ${ }^{[55]}$ 在研制 Simeprevir 的过程中, 通过对生 物电子等排体取代认真研究, 创造性地引入了三取代的 环戊二羰基核心基元, 打破了必含脯氨酸结构的通式 (图 7).<smiles>[R]NC(=O)C1CC(O)CC1C(=O)NC</smiles>

环戊烷<smiles>CCNC(=O)C1CC(O)C=C1C(N)=O</smiles>

环戊烯

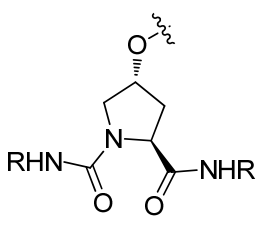

脯氨酸尿素

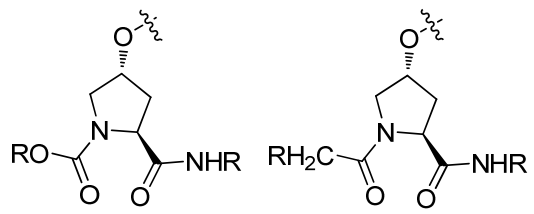

脯氨酸氨基甲酸酯脯氨酸酰胺

图 7 生物电子等排取代研究的创新

Figure 7 Innovative research for bioisosteric replacement

Simeprevir 先导化合物的优化策略从五个方面进 行: (1)脯氨酸尿素系列的更换; (2)药效团 P2 取代基的引 入和修饰; (3)环大小的控制; (4)多肽结构的减化和优化; (5)P1 酸生物电子等排变换(图 8).
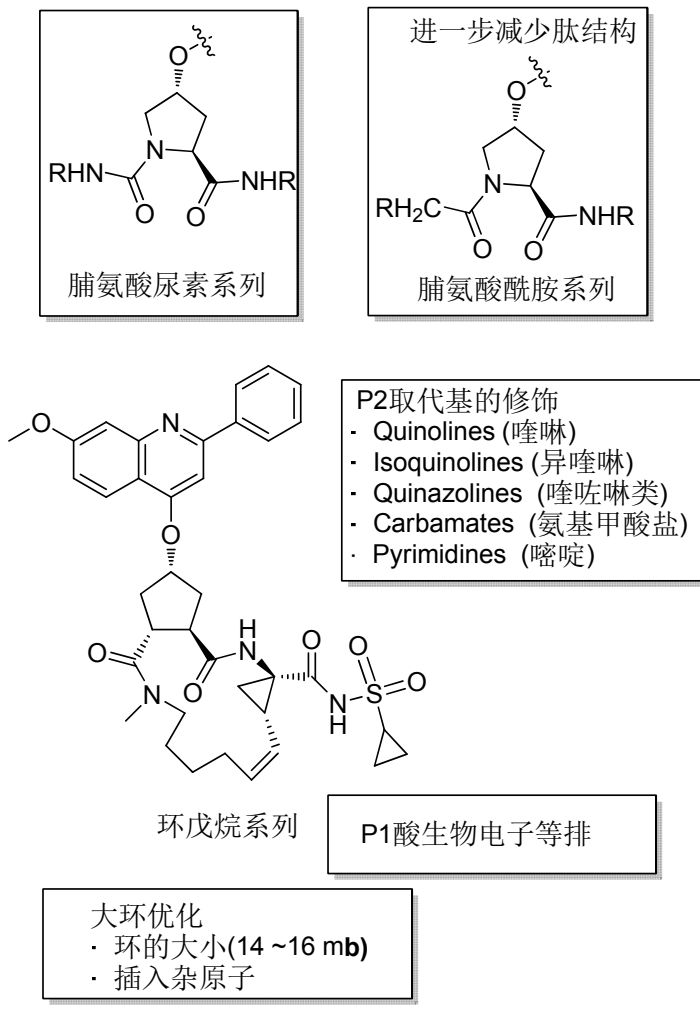

图 8 结构优化的五个方面

Figure 8 Lead optimization strategy

在不对称合成关键片段 $(1 R, 2 S)$-1-氨基-2-乙烯基环
丙基羧酸的骨架的过程中，默沙东制药(Merck)的工艺 化学家巧妙使用了无需过渡金属催化的手性相转移催 化下的绿色工艺，应用了以甘氨酸席夫碱和二溴丁烯为 原料的合成方法 ${ }^{[6]}$, 一步到位构筑了含有环丙烷基和 乙烯基的手性 $\alpha$ 氨基酸酯衍生物 174. 这也是默沙东制 药(Merck)的工艺化学家自在 20 世纪 80 年代中期第一次 将手性相转移技术引入药物合成以后的另一个成功案 例(Scheme 22) ${ }^{[57]}$.

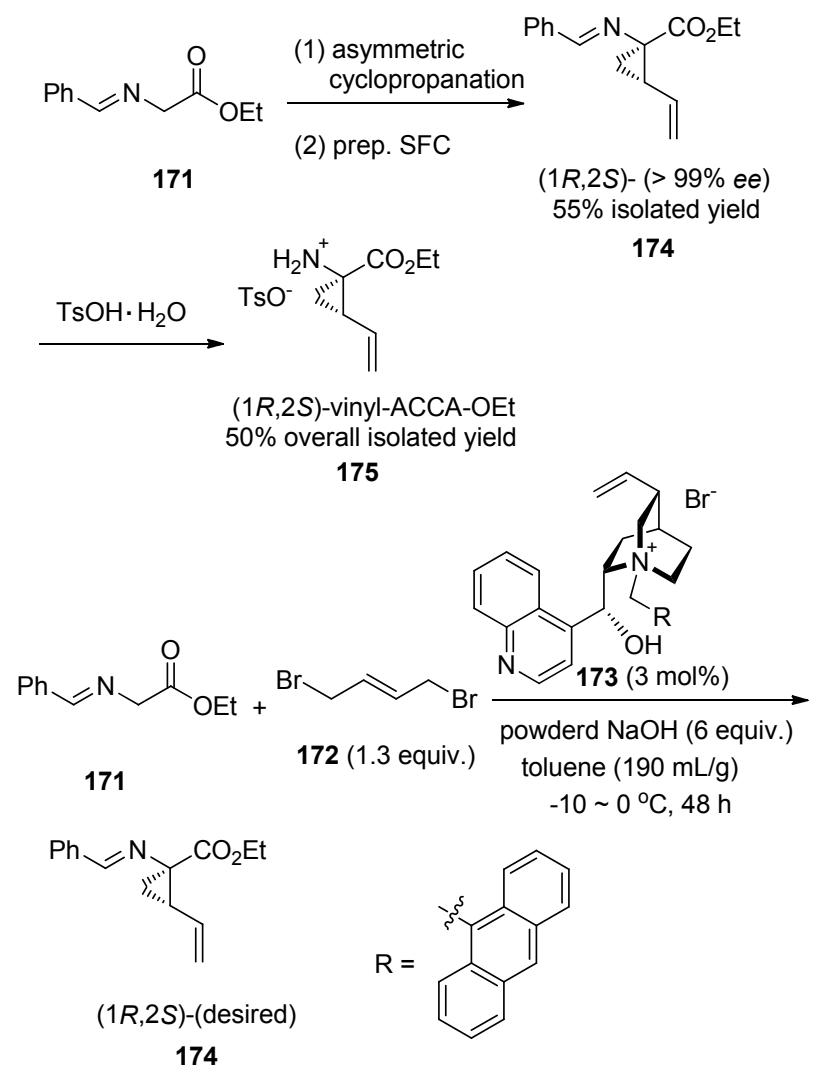

图式 22 手性相转移催化合成 $\alpha$-氨基酸酯衍生物 Scheme 22 Synthesis of $\alpha$-amino acid ester derivative catalyzed by chiral PTC

百时美施贵宝的工艺小组 ${ }^{[58]}$ 仔细研究了手性相转 移催化剂下进行不对称环丙基化反应的机理，他们发现 初始的烷基化反应并不是立体选择的，而随后的关环反 应形成环丙烷则是立体选择的. 他们分析了催化剂的降 解途径, 通过对化学过程的透彻研究, 采用切实可行的 拆解一一重结晶和酯的直接酰胺化一一重结晶过程, 开 发出一条简洁有效需要柱层析的工艺. 有效制备了关键 手性环丙烷 $\alpha$ 氨基酸中间体 $\mathbf{1 7 8}$ (Scheme 23).

闭环复分解(RCM) 反应是一种非常有效的合成各 种不饱和碳环和杂环化合物的方法. 随着各种性能优良 的催化剂的不断发展，尤其是含氮杂环卡宾配体的钉催 化剂的出现，使得闭关环复分解反应在合成复杂有机分 子、生物活性大分子以及天然产物等方面得到了极为广 


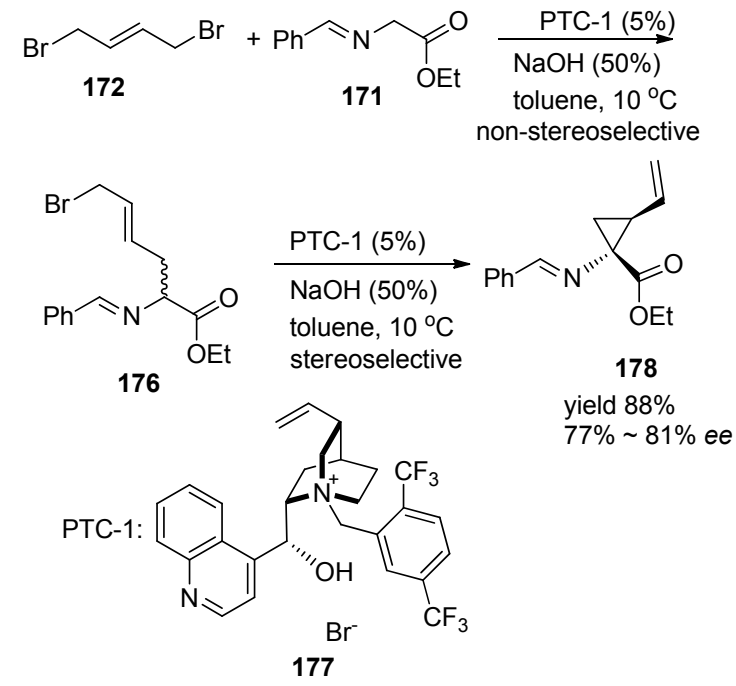

图式 23 手性相转移催化合成 $\alpha$-氨基酸酯衍生物

Scheme 23 Synthesis of $\alpha$-amino acid ester derivative catalyzed by chiral PTC

泛的应用 ${ }^{[59]}$. 在临床 3 期抗丙肝病毒 Danoprevir 的研发 过程中, 研发小组利用 RCM 关环策略, 成功制备了临 床药物 Danoprevir ${ }^{[60]}$ (Eq. 5).<smiles>C=C[C@@H]1C[C@]1(NC(=O)C1CC(O)CN1C(=O)[C@H](CCCCCC=CC(=O)O)NC(=O)OCc1ccccc1)C(=O)OCC</smiles><smiles>CCC/C=C\[C@@H]1C[C@]1(NC(=O)C1C[C@@H](O)CN1C(=O)[C@H](CCCC[18CH])NC(=O)OC(C)(C)C)C(=O)OCC</smiles>

药物化学家 Rosenquist 通过对 RCM 催化剂的篎选 和反应条件的优化, 极为有效地制备了大环内酰胺药物 Simeprevir (TMC435) ${ }^{[55]}$, 将反应的产率从 $47 \%$ 提高到 $85 \%$, 有机合成化学的专一性和高效性得到很好展示 (Scheme 24).

在使用烯烃复分解反应于 $\mathrm{HCV}$ 新药研发最为成功 的案例当属默沙东制药(Merck)的工艺研究小组, 他们 采用同时缓慢滴加 $\mathrm{Ru}$ 催化剂和二烯底物的方法, 极为 出色地生产了临床药物 Vaniprevir (MK 7009) ${ }^{[61]}$ (Scheme 25). 该策略的亮点为: 一是催化剂的用量很低
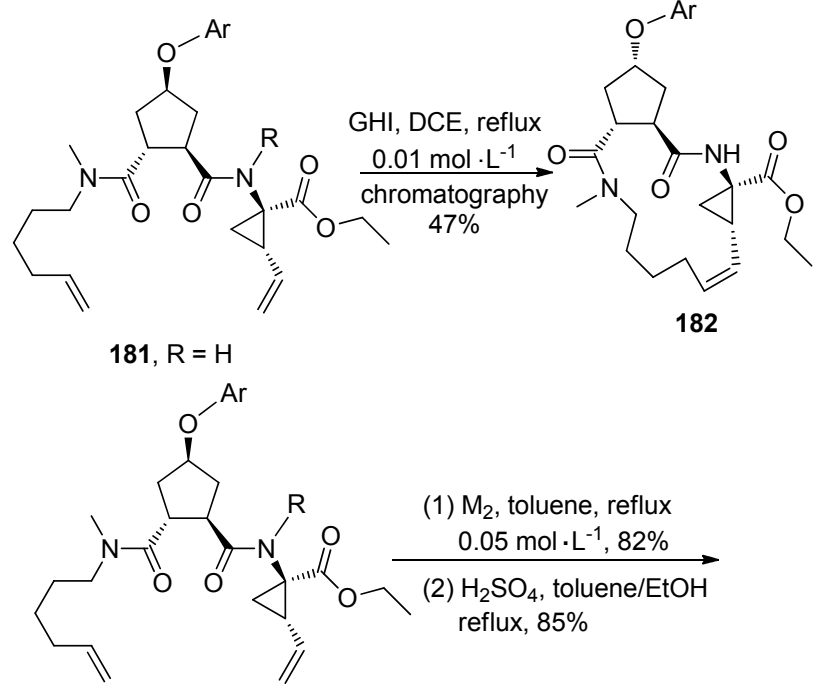

183, $\mathrm{R}=\mathrm{Boc}$

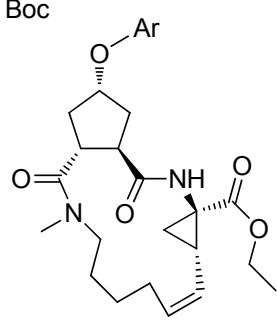

184

图式 24 闭环复分解制备大环内酰胺

Scheme 24 Ring closing metathesis to prepare macrocyclic lactam

$(0.2 \mathrm{~mol} \%)$; 二是底物浓度高 $\left(0.13 \mathrm{~mol} \cdot \mathrm{L}^{-1}\right)$, 不需要高 度稀释; 三是极为优秀的高产率 $(91 \%)$. 这充分体现了 现代药物合成的艺术.

抗丙肝新药研发的另外一个重要靶点是 NS5A, 进 度最快的是百时美施贵宝(BMS)、艾伯维(AbbVie)、吉 利德(Gilead)这三家公司的口服小分子新药(结构见图 9). 2014 年 7 月 BMS 公司开发的口服丙肝鸡尾酒疗法, 获批在日本上市, 之后又获得欧盟批准. 这种疗法结合 了 NS5A 抑制剂 Daclatasvir 和 NS3/4A 蛋白酶抑制剂 Asunaprevir $^{[62]}$, 主要用于治疗基因 1 型丙肝患者.

Daclatasvir 是一个创新的充满美感的对称性药物分 子(从二维结构来看, 它是具有对称性的, 但从三维来 看, 没有对称性, 是一个手性分子). 2010 年施贵宝研究 人员首先披露了 BMS-790052 即 Daclatasvir 的抗 HCV NS5A 病毒抑制剂的一些重要数据 ${ }^{[63]}$, 该药物是通过高 通量篮选从超过一百万个化合物中篮选出来的. 研发人 员发现分子对称性结构对抗病毒活性起着举足轻重的 作用 ${ }^{[64]}$.

为什么要设计出这样拥有对称性的新型抗丙肝病 毒药物? 最近的一些研究对这些疑惑有了进一步的解 释. 丙型肝炎病毒非结构功能蛋白 NS5A 是一个有对称 


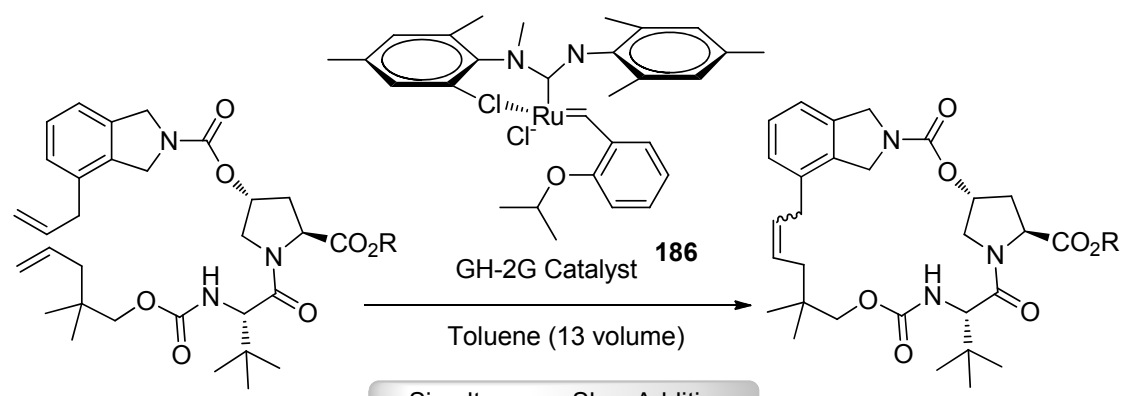

185, Diene

- Low Catalyst Loading ( $0.2 \mathrm{~mol} \%$ )

187, Macrocycle

- High Volume Product ivity $\left(0.13 \mathrm{~mol} \cdot \mathrm{L}^{-1}\right)$

High Chemical Yield (91\%)<smiles>CC[C@H](C)[C@](C)(NC(=O)C1C[C@@H](OC(=O)N2Cc3cccc(CCCCC(C)(C)COC(=O)N[C@@H](C(=O)NS(=O)(=O)C4CC4)C(C)(C)C)c3C2)CN1C(=O)NC1(C)CC1)C(C)(C)C</smiles>

166, Vaniprevir (MK-7009)

图式 25 Vaniprevir 的合成

Scheme 25 Synthesis of vaniprevir

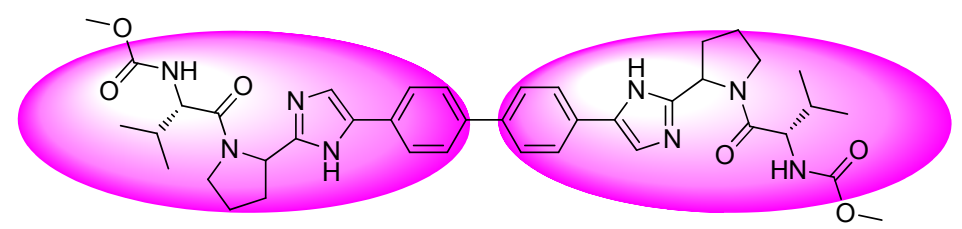

188, 达卡他韦(Daclatasvir, BMS)

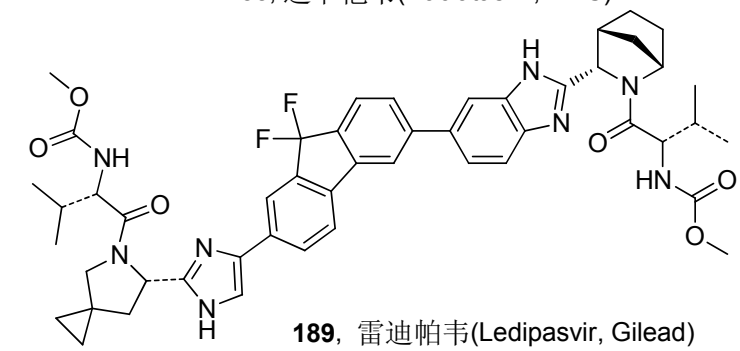

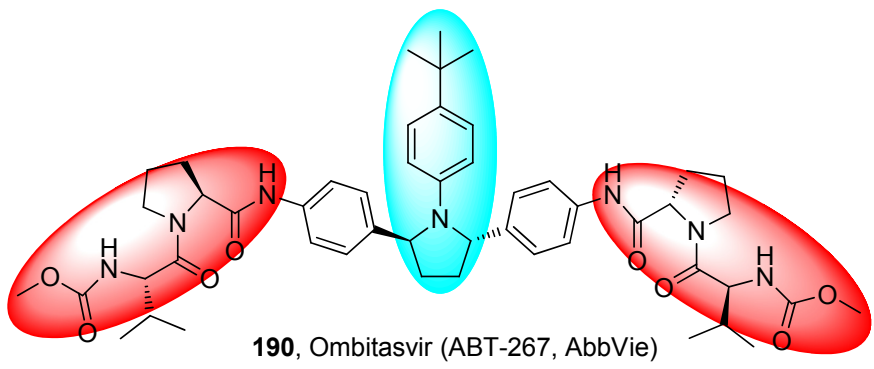

图 9 已上市的 NS5A 蛋白酶抑制剂药物

Figure 9 HCV NS5A inhibitors on the market

性的二聚体, Daclatasvir 的二聚体对称结构的 $\mathrm{N}$ 末端区 域将更加有效地作用于主要抵抗突变的 NS5A 病毒的 N 末端区域、包括螺旋结构和所在区间. 这样就抑制了病
毒的复制与感染. 最新的 $X$ 射线晶体结构也揭示了这一 区域有两个新的二聚体形成, 这也为未来的抗病毒药物 设计提供了理论支持. 
根据发表在美国国家科学院院刊(PNAS)所描述的 病毒动力学计算机模型, 新型丙型肝炎病毒 $(\mathrm{HCV})$ NS5A 抑制剂 Daclatasvir 作用于病毒复制过程, 从而实 现非常快速的 HCV RNA 的下降 ${ }^{[65]}$. 施贵宝研究人员利 用对称性使 Daclatasvir 合成迅速的简化 ${ }^{[66]}$, 而关键中间 体 191 的合成也许能使用钯催化的自我偶联或 $\mathrm{C}-\mathrm{H}$ 活
化的偶联法完成，合成化学家通过考察分子碎片的对称 性使合成原料趋向简单(Scheme 26). 药物合成的艺术 还表现在实现合成路径的多样性，创新药物 Daclatasvir 能够通过钯催化的 Suzuki 偶联反应来制备, 虽然步骤和 原料有一些变化 ${ }^{[66]}$ (Scheme 27).

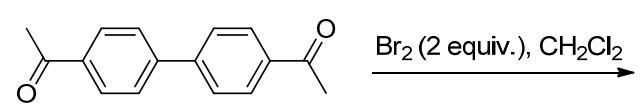

191<smiles>CC(C)(C)OC(=O)N1CCC[C@H]1C(=O)OCC(=O)c1ccc(-c2ccc(C(=O)COC(=O)C(C)(C)C)cc2)cc1</smiles>

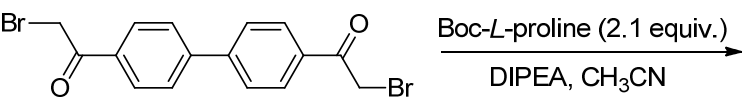

192<smiles>CC(C)(C)OC(=O)N1CCC[C@H]1c1ncc(-c2ccc(-c3ccc(-c4cnc([C@@H]5CCCN5C(=O)OC(C)(C)C)[nH]4)cc3)cc2)[nH]1</smiles>

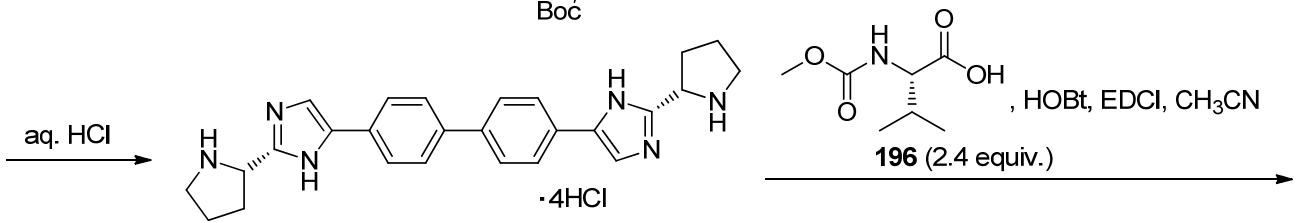

195<smiles>COC(=O)N[C@H](C(=O)N1CCC[C@H]1c1ncc(-c2ccc(-c3ccc(-c4cnc([C@@H]5CCCN5C(=O)[C@@H](NC(=O)OC)C(C)C)[nH]4)cc3)cc2)[nH]1)C(C)C</smiles>

图式 26 达卡他韦的合成路线(I)

Scheme 26 Synthesis of daclatasvir (I)

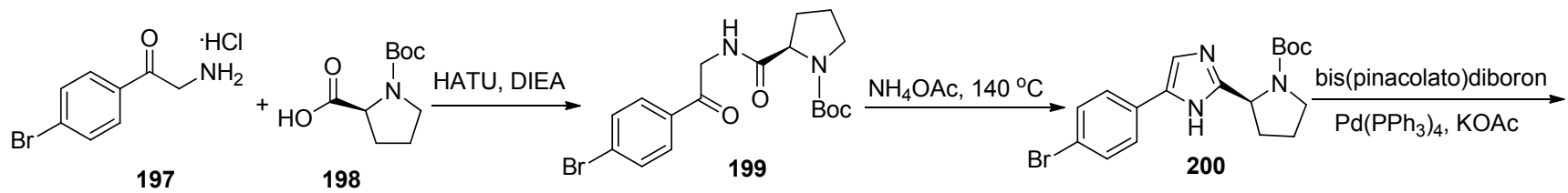<smiles>CC(C)(C)OC(=O)N1CCCC1c1ncc(-c2ccc(-c3ccc(-c4cnc(C5CCCN5C(=O)OC(C)(C)C)o4)cc3)cc2)[nH]1</smiles><smiles>COC(=O)CC(C(=O)N1CCCC1c1ncc(-c2ccc(-c3ccc(-c4cnc([C@@H]5CCCN5C(=O)C(NC(=O)OC)C(C)C)[nH]4)cc3)cc2)[nH]1)C(C)C(C)C(=O)OC</smiles>

图式 27 达卡他韦的合成路线(II)

Scheme 27 Synthesis of daclatasvir (II) 
吉利德制药 (Gilead) ${ }^{[67]}$ 发现新颖的非对称苯并咪 唑、二氟芴-咪唑为核心和远侧[2.2.1]氮杂双环系统组成 的 NS5A 强效抑制剂. 进一步优化抗病毒活性和药代性 质, 发现了 Ledipasvir (GS-5885), 化合物 GS-5885 具有 更长的半衰期: $t_{1 / 2}$ 为 $37 \sim 45 \mathrm{~h}$, 每日只需一次给药. GS-5885 已被证明是安全和有效的, 与具有互补机制直 接作用的抗病毒药物联合使用时, 其 SVR12[即治疗结 束后 12 周用灵敏的试剂检测不到 HCV RNA $(<15$ $\mathrm{IU} / \mathrm{mL})]$ 可高达 $100 \%$.

Ledipasvir 的合成也充分显示了现代合成方法在构 筑复杂药物分子中的威力, 使用溴代碘代荡, 在碱性条 件下通过 $N$-氟代双苯磺酰胺, 制备了二氟代芴 204, 随 后选择性地通过从 204 衍生的格氏试剂与 Weinreb 酰 胺 ( $N$-甲基- $N$-甲氧基氯代酰胺)的反应, 获得了氯甲基氟 代芴酮 205. 利用钯催化的 Suzuki 偶联反应, 吉利德制 药 (Gilead) 研究人员有效地制备了关键中间体 209 (Scheme 28). 2014 年 10 月 FDA 批准复方药物 Harvoni (Ledipasvir 和 Sofosbuvir)在美国上市.

2013 年 5 月美国 FDA 授予 AbbVie 丙肝鸡尾酒疗 法突破性疗法的认定, 这种疗法包括 ABT-450/Ritonavir 和 NS5A 抑制剂 Ombitasvir (ABT-267)和非核苷 NS5B 聚合酶抑制剂 Dasabuvir (ABT-333), 是一种全口服、无 干扰素的方案. 2014 年 6 月 FDA 又授予该疗法新药申请
(NDA) 优先审查资格. 值得一提的是 ABT-267 和百时美 施贵宝的 Daclatasvir一样, 是一个具有二维对称性的手 性分子, 其合成方法如 Scheme 29 所示 ${ }^{[68]}$. 值得一提的 是，对称的 1,4-二酮 212 是由简单的硝基苯甲基酮 211 和硝基苯溴甲基酮 210 经 $\mathrm{ZnCl}_{2}$ 催化的反应一步制备的, 虽然反应的收率有待提高. 随后经过不对称还原得到了 手性二醇 213, 经酯化得二甲磺酸酯 214, 氨化和环化反 应得到了关键中间体一光学活性的吡咯烷 217. 随后经 催化氢化、脱保护以及多肽偶联反应成功引入了脯氨酸 酰胺支链, 成功制备了 ABT-267, 合成可谓是快速有效.

\section{8 总结和展望}

生命科学日新月异地发展, 新化学手段和反应的创 新为药物合成带来了新的机遇和挑战. 在分子水平上认 识生命过程，调节生命过程中的信号传递，研发新的高 效低毒靶向性选择的创新药物、征服威胁人类的严重疾 病已成为当前药物创新的重要任务. 冊容置疑, 每一个 新药的诞生都是人类医药发展史上的里程碑. 创新药物 的发现之路是极其艰辛的, 不仅需要丰富的创造力、渊 博的科学知识和持之以恒的信念, 而且是一项异常艰苦 卓绝的探索活动. 在药物发现的历史长河中充满着曲折 的历程和趣味横生的故事.
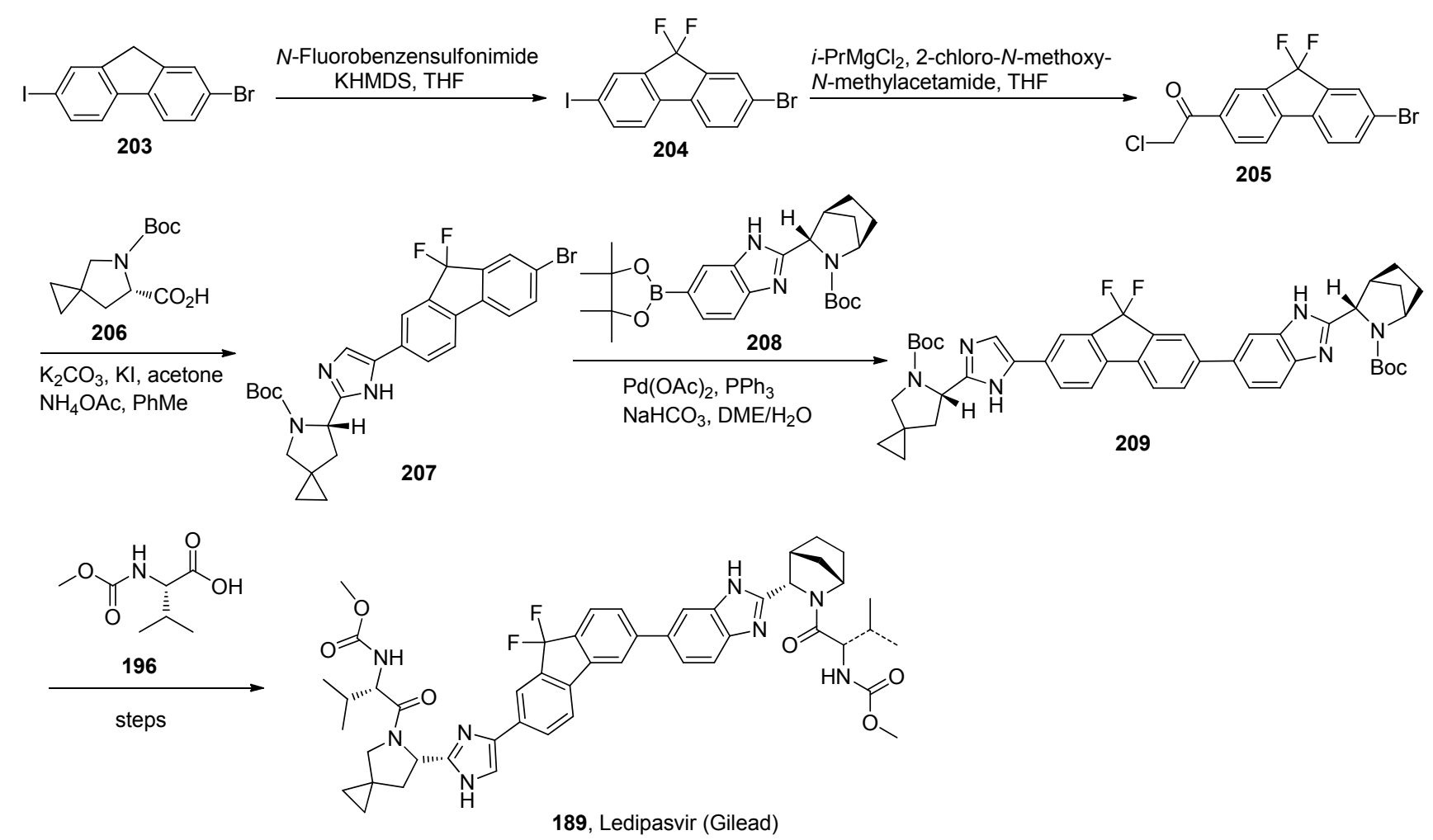

图式 28 雷迪帕韦的合成 Scheme 28 Synthesis of ledipasvir 


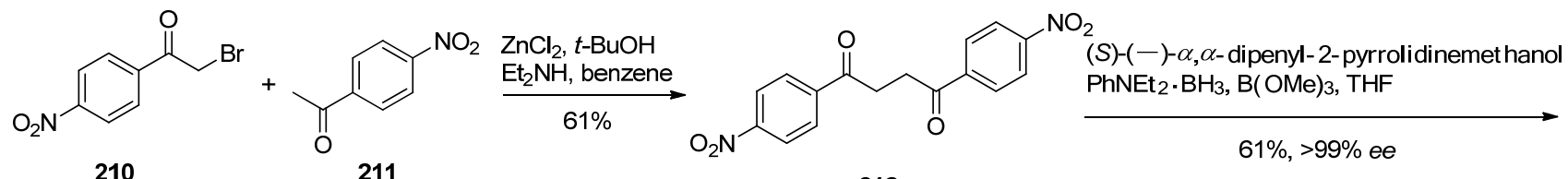

212

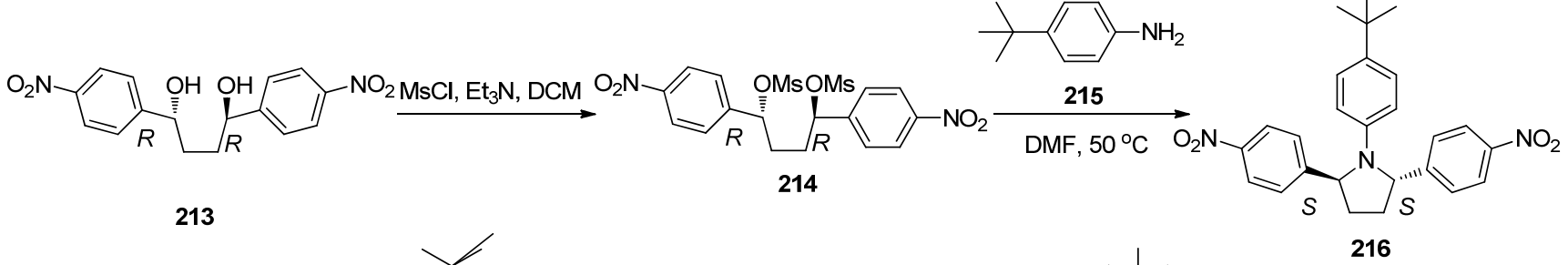

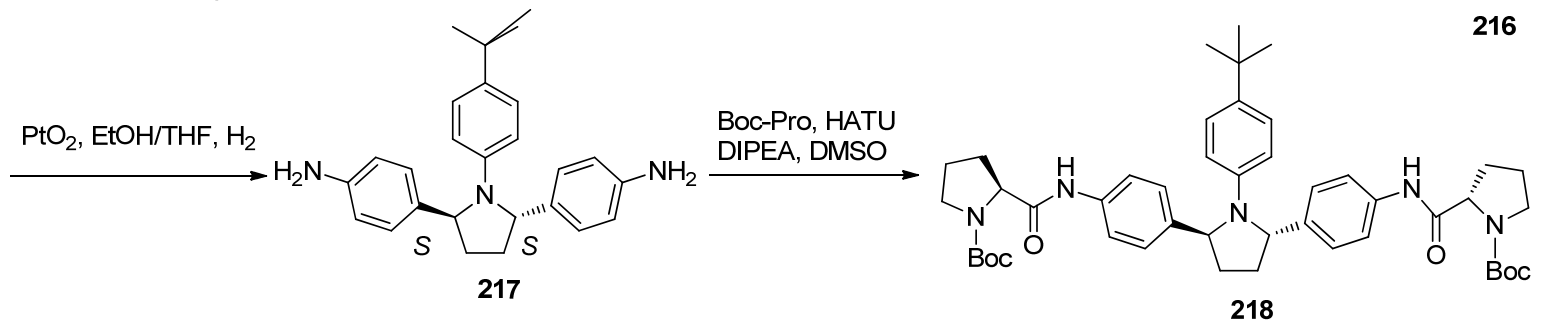

218

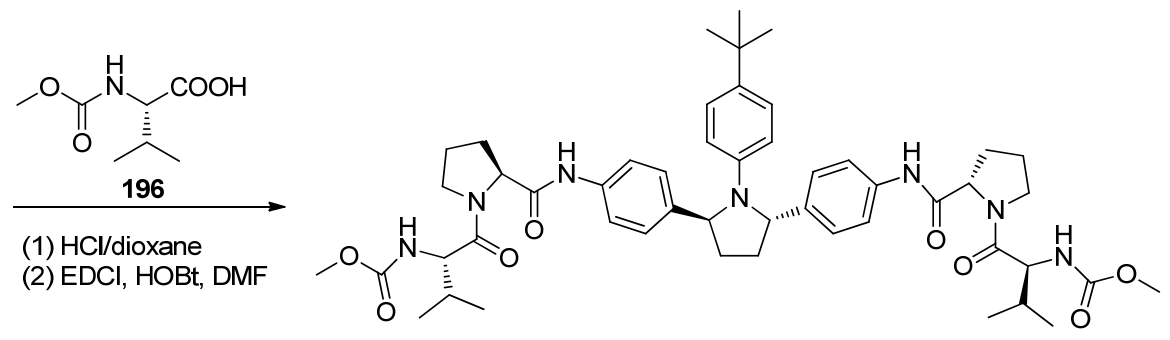

190, ABT-267(AbbVie)

图式 29 Ombitasvir (ABT-267)的合成

Scheme 29 Synthesis of ombitasvir (ABT-267)

有机合成是一门艺术 ${ }^{[69]}$, 从 Evans 手性助剂到现代 的不对称催化; 从 Heck 反应和 Suzuki 偶联到绿色的 $\mathrm{C}-\mathrm{H}$ 活化; 从 Sharpless 环氧化到点击化学; 从 Ullmann 反应到 Kumada 偶联、Buchwald-Hartwig 偶联、 Chan-Lam 偶联; 从经典的 Mannich、Ugi 多组分反应到 现代的有机硼酸参与的 Petasis 反应, 有机合成的技术手 段和研发进展日新月异. 药物化学家充分利用先进的合 成方法和技巧，在深刻认识疾病机理和治疗靶点的前提 下，创造性的设计、合成出一系列结构新颖、充满艺术 之美的药物分子, 在人类征服疾病痛楚的道路上取得一 次又一次的突破，拯救了千百万病人患者的宝贵生命， 这充分展现了药物化学家的高尚美德. 药物研发是一个 美好的事业, 希望有更多的优秀人才投身进来, 更希望 中国的药物化学与合成在不久的将来走在世界的前面!

\section{References}

[1] (a) Tremblay, J. F. Chem. Eng. News 2013, 91, 22.

(b) Huang, W. S.; Metcalf, C. A.; Sundaramoorthi, R.; Wang, Y.; Zou, D.; Thomas, R. M.; Zhu, X.; Cai, L.; Wen, D.; Liu, S.; Romero, J.; Qi, J.; Chen, I.; Banda, G.; Lentini, S. P.; Das, S.; Xu,
Q.; Keats, J.; Wang, F.; Wardwell, S.; Ning, Y.; Snodgrass, J. T.; Broudy, M. I.; Russian, K.; Zhou, T.; Commodore, L.; Narasimhan, N. I.; Mohemmad, Q. K.; Iuliucci, J.; Rivera, V. M.; Dalgarno, D. C.; Sawyer, T. K.; Clackson, T.; Shakespeare, W. C. J. Med. Chem. 2010, 53, 4701.

(c) Ying, W. W.; Du, Z. J.; Sun, L. J.; Foley, K. P.; Proia, D. A.; Blackman, R. K.; Zhou, D.; Inoue, T.; Tatsuta, N.; Sang, J.; Ye, S. X.; Acquaviva, J.; Ogawa, L. S.; Wada, Y.; Barsoum, J.; Koya, K. Mol. Cancer Ther. 2012, 11, 475

(d) Duan, J. X.; Jiao, H. L.; Kaizerman, J.; Stanton, T.; Evans, J. W.; Lan, L.; Lorente, G.; Banica, M.; Jung, D.; Wang, J. W.; Ma, H. Y.; Li, X. M.; Yang, Z. J.; Hoffman, R. M.; Ammons, W. S.; Hart, C. P.; Matteucci, M. J. Med. Chem. 2008, 51, 2412.

(e) Pento, J. T. Drugs Future 2011, 36, 663.

(f) Ding, K. L. Acta Chim. Sinica 2014, 72, 755 (in Chinese). (丁奎岭, 化学学报, 2014, 72, 755.)

[2] Pound, H. B.; Ho, V. Q.; Pinilla-Ibarz, J. Drugs Future 2011, 36 , 807.

[3] (a) Zhang, J.; Cue, B. W. Green Techniques for Organic Synthesis and Medicinal Chemistry, John Wiley \& Sons, West Sussex, United Kinadom, 2012, p. 631.

(b) Zhang, J.; Zhang, F. L. Chin. J. Pharm. 2013, 44, 1281 (in Chinese).

(张雯, 张福利, 中国医药工业杂志, 2013, 44, 1281.)

[4] Dunn, P. D.; Wells, A. S.; Williams, M. T. Green Chemistry in the Pharmaceutical Industry, Wiley-VCH, 2010. 
[5] (a) Bollag, G.; Tsai, J.; Zhang, J. Z.; Zhang, C.; Ibrahim, P.; Nolop, K.; Hirth, P. Nat. Rev. Drug Discovery 2012, 11, 873.

(b) Puzanov, I.; Flaherty, K. T.; Sosman, J. A.; Grippo, J. F.; Su, F.; Nolop, K.; Lee, R. J.; Bollag, G. Drugs Future 2011, 36, 191.

(c) Zhang, C.; Ibrahim, P. N.; Zhang, J. Z.; Burton, E. A.; Habets, G.; Zhang, Y.; Powell, B.; West, B. L.; Matusow, B.; Tsang, G.; Shellooe, R.; Carias, H.; Nguyen, H.; Marimuthu, A.; Zhang, K. Y. J.; Oh, A.; Bremer, R.; Hurt, C. R.; Artis, D. R.; Wu, G. X.; Nespi, M.; Spevak, W.; Lin, P.; Nolop, K.; Hirth, P.; Tesch, G. H.; Bollag, G. Proc. Natl. Acad. Sci. U. S. A. 2013, 110, 5689.

(d) Tsai, J.; Lee, J. T.; Wang, W. R.; Zhang, J. Z.; Cho, H.; Mamo, S.; Bremer, R.; Gillette, S.; Kong, J.; Haass, N. K.; Sproesser, K.; Li, L.; Smalley, K. S. M.; Fong, D.; Zhu, Y. L.; Marimuthu, A.; Nguyen, H.; Lam, B.; Liu, J.; Cheung, I.; Rice, J.; Suzuki, Y.; Luu, C.; Settachatgul, C.; Shellooe, R.; Cantwell, J.; Kim, S. H.; Schlessinger, J.; Zhang, K. Y. J.; West, B. L.; Powell, B.; Habets, G.; Zhang, C.; Ibrahim, P. N.; Hirth, P.; Artis, D. R.; Herlyn, M.; Bollag, G. Proc. Natl. Acad. Sci. U. S. A. 2008, 105, 3041.

[6] (a) Zhang, J.; Jin, C. F.; Zhang, Y. J. Chin. J. Org. Chem. 2014, 34, 662 (in Chinese).

(张雯，金传飞，张英俊，有机化学, 2014, 34, 662.)

(b) Begue, J.-P.; Bonnet-Delpon, D. J. Fluorine Chem. 2006, 127, 992.

[7] Tran, C.; Ouk, S.; Clegg, N. J.; Chen, Y.; Watson, P. A.; Arora, V.; Wongvipat, J.; Smith-Jones, P. M.; Yoo, D.; Kwon, A.; Wasielewska, T.; Welsbie, D.; Chen, C. D.; Higano, C. S.; Beer, T. M.; Hung, D. T.; Scher, H. I.; Jung, M. E.; Sawyers, C. L. Science 2009, 324, 787.

[8] Marcian, E. V. D.; Diane, M. R.; Bess, W. J. Med. Chem. 2000, 43, 3344.

[9] Michael, E. J.; Samedy, O.; Dongwon, Y.; Charles, L. S.; Charlie, C.; Chris, T.; John, W. J. Med. Chem. 2010, 53, 2779.

[10] Jain, R. P.; Angelaud, R. WO 2011106570, 2011 [Chem. Abstr. 2011, 155, 380335].

[11] (a) Sun, L.; Liang, C.; Shirazian, S.; Zhou, Y.; Miller, T.; Cui, J.; Fukuda, J. Y.; Chu, J. Y.; Nematalla, A.; Wang, X. Y.; Chen, H.; Sistla, A.; Luu, T. C.; Tang, F.; Wei, J.; Tang, C. J. Med. Chem. 2003, 46, 1116.

(b) Mclntyre, J. A.; Castaner, J. Drugs Future 2005, 30, 785.

[12] O'Bryant, C. L.; Wenger, S. D.; Kim, M.; Thompson, L. A. Ann. Pharmacother. 2013, 47, 189.

[13] Deng, X. M.; Okram, B.; Ding, Q. A.; Zhang, J. M.; Choi, Y. M.; Adrian, F. J.; Wojciechowski, A.; Zhang, G. B.; Che, J. W.; Bursulaya, B.; Cowan-Jacob, S. W.; Rummel, G.; Sim, T.; Gray, N. S. J. Med. Chem. 2010, 53, 6934.

[14] Bilbro, J.; Mart, M.; Kyprianou, N. Anticancer Res. 2013, 33, 4695.

[15] Sun, C. L.; Christensen, J,-G.; McMahon, G. In Kinase Inhibitor Drugs, Eds.: Li, R. S.; Stafford, A. J., Hoboken, New Jersey, USA, 2009, p. 1.

[16] Manley, J. M.; Kalman, M. J.; Conway, B. G.; Ball, C. C.; Havens, J. L.; Vaidyanathan, R. J. Org. Chem. 2003, 68, 6447

[17] Vaidyanathan, R. In Process Chemistry in the Pharmaceutical Industry, Eds.: Gadamasetti, K.; Braish, T., Boca Roton, Florida, USA, 2008, p. 49.

[18] Pettersson, M. In Modern Drug Synthesis, Eds.: Li, J. J.; Johnson, S. D., Hoboken, New Jersey, USA, 2010, p. 87.

[19] (a) Cui, J. J.; Tran-Dube, M.; Shen, H.; Nambu, M.; Kung, P. P.; Pairish, M.; Jia, L.; Meng, J.; Funk, L.; Botrous, I.; McTigue, M.; Grodsky, N.; Ryan, K.; Padrique, E.; Alton, G.; Timofeevski, S.; Yamazaki, S.; Li, Q. H.; Zou, H. L.; Christensen, J.; Mroczkowski, B.; Bender, S.; Kania, R. S.; Edwards, M. P. J. Med. Chem. 2011, 54,6342 . (b) Nwizu, T.; Kanteti, R.; Kawada, I.; Rolle, C.; Vokes, E. E.; Salgia, R. Drugs Future 2011, 36, 91.

[20] (a) Cue, B. W.; Zhang, J. Green Chem. Lett. Rev. 2009, 2, 193. (b) Zhang, J.; Zhang, F. L. Chin. J. Pharm. 2013, 44, 814 (in Chinese).

(张雯，张福利，中国医药工业杂志, 2013, 44, 814.)

[21] Huang, Q.; Johnson, T. W.; Bailey, S.; Brooun, A.; Bunker, K. D.; Burke, B. J.; Collins, M. R.; Cook, A. S.; Cui, J. J.; Dack, K. N.; Deal, J. G.; Deng, Y.-L.; Dinh, D.; Engstrom, L. D.; He, M.; Hoffman, J.; Hoffman, R. L.; Johnson, P. S.; Kania, R. S.; Lam, H.; Lam, J. L.; Le, P. T.; Li, Q.; Lingardo, L.; Liu, W.; Lu, M. W.; McTigue, M.; Palmer, C. L.; Richardson, P. F.; Sach, N. W.; Shen, H.; Smeal, T.; Smith, G. L.; Stewart, A. E.; Timofeevski, S.; Tsaparikos, K.; Wang, H.; Zhu, H.; Zhu, J.; Zou, H. Y.; Edwards, M. P. J. Med. Chem. 2014, 57, 1170.

[22] (a) Xie, J. H.; Zhou, Q. L. Acta Chim. Sinica 2014, 72, 778 (in Chinese).

(谢建华, 周其林, 化学学报, 2014, 72, 778.)

(b) Qian, J. Q.; Yan, P. C.; Che, D. Q.; Zhou, Q. L.; Li, Y. Q. Tetrahedron Lett. 2014, 55, 1528.

[23] de Koning, P. D.; McAndrew, D.; Moore, R.; Moses, I. B.; Boyles, D. C.; Kissick, K.; Stanchina, C. L.; Cuthbertson, T.; Kamatani, A.; Rahman, L.; Rodriguez, R.; Urbina, A.; Sandoval, A.; Rose, P. R. Org. Process Res. Dev. 2011, 15, 1018.

[24] Washburn, W. N. J. Med. Chem. 2009, 52, 1785.

[25] Nomura, S.; Sakamaki, S.; Hongu, M.; Kawanishi, E.; Koga, Y.; Sakamoto, T.; Yamamoto, Y.; Ueta, K.; Kimata, H.; Nakayama, K.; Tsuda-Tsukimoto, M. J. Med. Chem. 2010, 53, 6355.

[26] Meng, W.; Ellsworth, B. A.; Nirschl, A. A.; McCann, P. J.; Patel, M.; Girotra, R. N.; Wu, G.; Sher, P. M.; Morrison, E. P.; Biller, S. A.; Zahler, R.; Deshpande, P. P.; Pullockaran, A.; Hagan, D. L.; Morgan, N.; Taylor, J. R.; Obermeier, M. T.; Humphreys, W. G.; Khanna, A.; Discenza, L.; Robertson, J. G.; Wang, A.; Hang, S.; Wetterau, J. R.; Janovitz, E. B.; Flint, O. P.; Whaley, J. M.; Washburn, W. N. J. Med. Chem. 2008, 51, 1145.

[27] Ohtake, Y.; Sato, T.; Kobayashi, T.; Nishimoto, M.; Taka, N.; Takano, K.; Yamamoto, K.; Ohmori, M.; Yamaguchi, M.; Takami, K.; Yeu, S.-Y.; Ahn, K.-H.; Matsuoka, H.; Morikawa, K.; Suzuki, M.; Hagita, H.; Ozawa, K.; Yamaguchi, K.; Kato, M.; Ikeda, S. J. Med. Chem. 2012, 55, 7828.

[28] Crich, D.; Wu, B. Org. Lett. 2006, 8, 4879.

[29] Deshpande, P. P.; Ellsworth, B. A.; Buono, F. G.; Pullockaran, A.; Singh, J.; Kissick, T. P.; Huang, M. H.; Lobinger, H.; Denzel, T.; Mueller, R. H. J. Org. Chem. 2007, 72, 9746.

[30] Deshpande, P. P.; Singh, J.; Pullockaran, A.; Kissick, T.; Ellsworth, B. A.; Gougoutas, J. Z.; Dimarco, J.; Fakes, M.; Reyes, M.; Lai, C. J.; Lobinger, H.; Denzel, T.; Ermann, P.; Crispino, G.; Randazzo, M.; Gao, Z. R.; Randazzo, R.; Lindrud, M.; Rosso, V.; Buono, F.; Doubleday, W. W.; Leun, S.; Richberg, P.; Hughes, D.; Washburn, W. N.; Meng, W.; Volk, K. J.; Mueller, R. H. Org. Process Res. Dev. 2012, 16, 577.

[31] Lemaire, S.; Houpis, I. N.; Xiao, T. T.; Li, J. J.; Digard, E.; Gozlan, C.; Liu, R. M.; Gavryushin, A.; Diene, C.; Wang, Y. C.; Farina, V.; Knochel, P. Org. Lett. 2012, 14, 1480.

[32] Madela, K.; McGuigan, C. Future Med. Chem. 2012, 4, 625.

[33] (a) Ferraris, D.; Duvall, B.; Delahanty, G.; Mistry, B.; Alt, J.; Rojas, C.; Rowbottom, C.; Sanders, K.; Schuck, E.; Huang, K.-C.; Redkar, S.; Slusher, B. B.; Tsukamoto, T. J. Med. Chem. 2014, 57, 2582.

(b) Liu, P.; Sharon, A.; Chu, C. K. J. Fluorine Chem. 2008, 129, 743.

[34] (a) Jordheim, L. P.; Durantel, D.; Zoulim, F.; Dumontet, C. Nat. 
Rev. Drug Discovery 2013, 12, 447.

(b) Mueller, K.; Faeh, C.; Diederich, F. Science 2007, 317, 1881.

[35] Sofia, M. J.; Bao, D.; Chang, W.; Du, J. F.; Nagarathnam, D.; Rachakonda, S.; Reddy, P. G.; Ross, B. S.; Wang, P. Y.; Zhang, H. R.; Bansal, S.; Espiritu, C.; Keilman, M.; Lam, A. M.; Steuer, H. M. M.; Niu, C. R.; Otto, M. J.; Furman, P. A. J. Med. Chem. 2010 53, 7202.

[36] Bobeck, D. R.; Schinazi, R. F.; Coats, S. J. Antiviral Ther. 2010, $15,935$.

[37] Ross, B. S.; Sofia, M.; Joseph; P.; Ganapati R.; Rachakonda, S.; Zhang, H.-R.; Chun, B.-K.; Wang, P. WO 2010135569, 2010 [Chem. Abstr. 2010, 154, 11258].

[38] Ross, B. S.; Reddy, P. G.; Zhang, H. R.; Rachakonda, S.; Sofia, M. J. J. Org. Chem. 2011, 76, 8311.

[39] Peifer, M.; Berger, R.; Shurtleff, V. W.; Conrad, J. C.; MacMillan, D. W. C. J. Am. Chem. Soc. 2014, 136, 5900.

[40] (a) Price, K. E.; Larrivee-Aboussafy, C.; Lillie, B. M.; McLaughlin, R. W.; Mustakis, J.; Hettenbach, K. W.; Hawkins, J. M.; Vaidyanathan, R. Org. Lett. 2009, 11, 2003.

(b) Cai, W. L.; Colony, J. L.; Kendall, P. M.; Krishnan, A. M.; Makowski, T.; Mazur, D. J.; Phillips, J.; Ripin, D. H. B.; Ruggeri, S. G.; Stearns, J. F.; White, T. D. Org. Process Res. Dev. 2005, 9, 51.

[41] (a) Campas-Moya, C. Drugs Future 2010, 35, 457.

(b) Yang, L. P. H.; Keating, G. M. Drugs. 2012, 72, 2117.

[42] Lin, Q. Y.; Meloni, D.; Pan, Y. C.; Xia, M.; Rodgers, J.; Shepard, S.; Li, M.; Galya, L.; Metcalf, B.; Yue, T. Y.; Liu, P. L.; Zhou, J. Org. Lett. 2009, 11, 1999.

[43] Ager, D. J.; Prakash, I.; Schaad, D. R. Aldrichim. Acta 1997, 30, 3.

[44] (a) Burness, C. B.; Perry, C. M. Drugs 2014, 74, 243.

(b) Zhang, J.; Crawford, J. In Modern Drug Synthesis, Eds.: Li, J. J.; Johnson, S. D., Hoboken, New Jersey, USA, 2010, p. 191.

[45] Renslo, A. R. Expert Rev. Anti-Infect. Ther. 2010, 8, 565.

[46] (a) Barbachyn, M. R.; Cleek, G. J.; Dolak, L. A.; Garmon, S. A.; Morris, J.; Seest, E. P.; Thomas, R. C.; Toops, D. S.; Watt, W.; Wishka, D. G.; Ford, C. W.; Zurenko, G. E.; Hamel, J. C.; Schaadt, R. D.; Stapert, D.; Yagi, B. H.; Adams, W. J.; Friis, J. M.; Slatter, J. G.; Sams, J. P.; Oien, N. L.; Zaya, M. J.; Wienkers, L. C.; Wynalda, M. A. J. Med. Chem. 2003, 46, 284.

(b) Brickner, S. J.; Hutchinson, D. K.; Barbachyn, M. R.; Manninen, P. R.; Ulanowicz, D. A.; Garmon, S. A.; Grega, K. C.; Hendges, S. K.; Toops, D. S.; Ford, C. W.; Zurenko, G. E. J. Med. Chem. 1996, 39, 673.

[47] Barbachyn, M. R.; Ford, C. W. Angew. Chem., Int. Ed. 2003, 42, 2010 .

[48] (a) Kanafani, Z. A. Corey, G. R. Expert Opin. Invest. Drugs 2012, 21,515 .

(b) Im, W. B.; Choi, S. H.; Park, J. Y.; Choi, S. H.; Finn, J.; Yoon, S. H. Eur. J. Med. Chem. 2011, 46, 1027.

[49] Shaw, K. J.; Barbachyn, M. R. Ann. N. Y. Acad. Sci. 2011, 24, 48.

[50] (a) Roehrig, S.; Straub, A.; Pohlmann, J.; Lampe, T.; Pernerstorfer, J.; Schlemmer, K. H.; Reinemer, P.; Perzborn, E. J. Med. Chem. 2005, 48, 5900 .

(b) Escolar, G.; Villalta, J.; Casals, F.; Bozzo, J.; Serradell, N.; Bolos, J. Drugs Future 2006, 31, 484.

[51] Birerdinc, A.; Younossi, Z. M. Expert Opin. Emergery Drugs 2010, 15,535 .

[52] Wang, Y.-K.; Rigat, K. L.; Sun, J.-H.; Gao, M.; Roberts, S. B. Arch. Biochem. Biophys. 2008, 470, 146.

[53] Grillot, A.-L.; Farmer, L. J.; Rao, B. G.; Taylor, W. P.; Weisberg, I. S.; Jacobson, I. M.; Perni, R. B.; Kwong, A. D. In Antiviral Drugs: From Basic Discovery through Clinical Trials, Ed.: Kazmierski, W.
M., Hoboken, New Jersey, USA. 2011, p. 207.

[54] Venkatraman, S.; Bogen, S. L.; Arasappan, A.; Bennett, F.; Chen, K.; Jao, E.; Liu, Y.-T.; Lovey, R.; Hendrata, S.; Huang, Y.; Pan, W.; Parekh, T.; Pinto, P.; Popov, V.; Pike, R.; Ruan, S.; Santhanam, B.; Vibulbhan, B.; Wu, W.; Yang, W.; Kong, J.; Liang, X.; Wong, J.; Liu, R.; Butkiewicz, N.; Chase, R.; Hart, A.; Agrawal, S.; Ingravallo, P.; Pichardo, J.; Kong, R.; Baroudy, B.; Malcolm, B.; Guo, Z.; Prongay, A.; Madison, V.; Broske, L.; Cui, X.; Cheng, K.-C.; Hsieh, T. Y.; Brisson, J.-M.; Prelusky, D.; Korfmacher, W.; White, R.; Bogdanowich-Knipp, S.; Pavlovsky, A.; Bradley, P.; Saksena, A. K.; Ganguly, A.; Piwinski, J.; Girijavallabhan, V.; Njoroge, F. G. J. Med. Chem. 2006, 49, 6074.

[55] Rosenquist, A.; Samuelsson, B.; Johansson, P. O.; Cummings, M. D.; Lenz, O.; Raboisson, P.; Simmen, K.; Vendeville, S.; de Kock, H.; Nilsson, M.; Horvath, A.; Kalmeijer, R.; de la Rosa, G.; Beumont-Mauviel, M. J. Med. Chem. 2014, 57, 1673.

[56] Belyk, K. M.; Xiang, B. P.; Bulger, P. G.; Leonard, W. R. Jr.; Balsells, J.; Yin, J. J.; Chen, C. Y. Org. Process Res. Dev. 2010, 14, 692.

[57] Dolling, U. H.; Davis, P.; Grabowski, E. J. Am. Chem. Soc. 1984, $106,446$.

[58] Lou, S.; Cuniere, N.; Su, B. N.; Hobson, L. A. Org. Biomol. Chem. 2013, 11, 6796.

[59] (a) Chauvin, Y. Angew. Chem., Int. Ed. 2006, 45, 3740.

(b) Schrock, R. R. Angew. Chem., Int. Ed. 2006, 45, 3748.

(c) Grubbs, R. H. Angew. Chem., Int. Ed. 2006, 45, 3760.

[60] Jiang, Y. T.; Andrews, S. W.; Condroski, K. R.; Buckman, B.; Serebryany, V.; Wenglowsky, S.; Kennedy, A. L.; Madduru, M. R.; Wang, B.; Lyon, M.; Doherty, G. A.; Woodard, B. T.; Lemieux, C.; Do, M. G.; Zhang, H. L.; Ballard, J.; Vigers, G.; Brandhuber, B. J.; Stengel, P.; Josey, J. A.; Beigelman, L.; Blatt, L.; Seiwert, S. D. J. Med. Chem. 2014, 57, 1753.

[61] (a) Kong, J.; Chen, C. Y.; Balsells-Padros, J.; Cao, Y.; Dunn, R. F.; Dolman, S. J.; Janey, J.; Li, H. M.; Zacuto, M. J. J. Org. Chem. 2012, 77, 3820.

(b) Song, Z. G. J.; Tellers, D. M.; Journet, M.; Kuethe, J. T.; Lieberman, D.; Humphrey, G.; Zhang, F.; Peng, Z. H.; Waters, M. S.; Zewge, D.; Nolting, A.; Zhao, D. L.; Reamer, R. A.; Dormer, P. G.; Belyk, K. M.; Davies, I. W.; Devine, P. N.; Tschaen, D. M. J. Org. Chem. 2011, 76, 7804.

[62] Reviriego, C. Drugs Future 2012, 37, 247.

[63] Gao, M.; Nettles, R. E.; Belema, M.; Snyder, L. B.; Nguyen, V. N.; Fridell, R. A.; Serrano-Wu, M. H.; Langley, D. R.; Sun, J. H.; O'Boyle, D. R.; Lemm, J. A.; Wang, C. F.; Knipe, J. O.; Chien, C.; Colonno, R. J.; Grasela, D. M.; Meanwell, N. A.; Hamann, L. G. Nature 2010, 465, 96.

[64] (a) Lemm, J. A.; O'Boyle, D.; Liu, M. P.; Nower, P. T.; Deshpande, M. S.; Snyder, L. B.; Martin, S. W.; Laurent, D. R. S.; Serrano-Wu, M. H.; Romine, J. L.; Meanwell, N. A.; Gao, M. J. Virol. 2010, 84, 482.

(b) Lemm, J. A.; Leet, J. E.; O'Boyle, D. R., II; Romine, J. L.; Huang, X. S.; Schroeder, D. R.; Alberts, J.; Cantone, J. L.; Sun, J.-H.; Nower, P. T.; Martin, S. W.; Serrano-Wu, M. H.; Meanwell, N. A.; Snyder, L. B.; Gao, M. Antimicrob. Agents Chemother. 2011, 55, 3795.

(c) Lambert, S. M.; Langley, D. R.; Garnett, J. A.; Angell, R.; Hedgethorne, K.; Meanwell, N. A.; Matthews, S. J. Protein Sci. 2014, 23, 723 .

[65] Guedj, J.; Dahari, H.; Rong, L. B.; Sansone, N. D.; Nettles, R. E.; Cotler, S. J.; Layden, T. J.; Uprichard, S. L.; Perelson, A. S. Proc. Natl. Acad. Sci. U. S. A. 2013, 110, 3991.

[66] (a) Belema, M.; Nguyen, V. N.; Bachand, C.; Deon, D. H.; 
Goodrich, J. T.; James, C. A.; Lavoie, R.; Lopez, O. D.; Martel, A.; Romine, J. L.; Ruediger, E. H.; Snyder, L. B.; St Laurent, D. R.; Yang, F. K.; Zhu, J. L.; Wong, H. S.; Langley, D. R.; Adams, S. P.; Cantor, G. H.; Chimalakonda, A.; Fura, A.; Johnson, B. M.; Knipe, J. O.; Parker, D. D.; Santone, K. S.; Fridell, R. A.; Lemm, J. A.; O'Boyle, D. R.; Colonno, R. J.; Gao, M.; Meanwell, N. A.; Hamann, L. G. J. Med. Chem. 2014, 57, 2013.

(b) Belema, M.; Lopez, O. D.; Bender, J. A.; Romine, J. L.; St Laurent, D. R.; Langley, D. R.; Lemm, J. A.; O'Boyle, D. R.; Sun, J. H.; Wang, C. F.; Fridell, R. A.; Meanwell, N. A. J. Med. Chem. 2014, 57, 1643.

(c) Reviriego, C. Drugs Future 2011, 36, 735.

[67] Link, J. O.; Taylor, J. G.; Xu, L. H.; Mitchell, M.; Guo, H. Y.; Liu, H. T.; Kato, D.; Kirschberg, T.; Sun, J. Y.; Squires, N.; Parrish, J. Keller, T.; Yang, Z. Y.; Yang, C.; Matles, M.; Wang, Y. J.; Wang,
K.; Cheng, G. F.; Tian, Y.; Mogalian, E.; Mondou, E.; Cornpropst, M.; Perry, J.; Desai, M. C. J. Med. Chem. 2014, 57, 2033.

[68] DeGoey, D. A.; Randolph, J. T.; Liu, D. C.; Pratt, J.; Hutchins, C.; Donner, P.; Krueger, A. C.; Matulenko, M.; Patel, S.; Motter, C. E.; Nelson, L.; Keddy, R.; Tufano, M.; Caspi, D. D.; Krishnan, P.; Mistry, N.; Koev, G.; Reisch, T. J.; Mondal, R.; Pilot-Matias, T.; Gao, Y.; Beno, D. W. A.; Maring, C. J.; Molla, A.; Dumas, E.; Campbell, A.; Williams, L.; Collins, C.; Wagner, R.; Kati, W. M. J. Med. Chem. 2014, 57, 2047.

[69] (a) Xing, Q. Y. Chemistry 1982, 9, 4 (in Chinese). (邢其毅, 化学通报, 1982, 9, 4.)

(b) Zong, R. S. Chemistry 1980, 6, 59 (in Chinese).

(宗汝实, 化学通报, 1980, 6, 59.)

(c) Zhang, J.; Yin, C. L. Chemistry 1991, 9, 1 (in Chinese).

(张雯, 尹承烈, 化学通报, 1991, 9, 1.) 